\title{
Stabilization Policies and Long Term Growth: Policy Implications from an Agent-based Macroeconomic Model
}

\author{
Philipp Harting
}




\title{
Stabilization Policies and Long Term Growth: Policy Implications from an Agent-based Macroeconomic Model*
}

\author{
Philipp Harting ${ }^{\dagger}$
}

Version: May 2015

\begin{abstract}
Do fiscal stabilization policies affect the long-term growth of the economy? If so, are the long-term effects growth-enhancing or growth-reducing? These questions have again become relevant to the political and academic debate since governments have been forced to spend considerable funds for economic stimulus packages as a response to the recent economic crisis. The answers provided by the economic literature are inconclusive. But a general observation is that, while the theoretical literature has emphasized the importance of structural issues as, e.g., the modeling approach of endogenous technological change, less attention has been paid to an elaborate design of the considered fiscal stabilization policies. This paper uses a closed agent-based macroeconomic model that generates endogenous business cycles to emphasize the role of the policy design for long-term growth effects of stabilization policies. By comparing a demand-oriented consumption policy and two different investment subsidizing policies, we can show that the considered policies are equally successful in smoothing the business cycle, but have different implications for the medium and long-term growth of the economy. Hence, not only modeling assumptions as stressed by the literature but also the concrete implementation of the policy seems to be important for the analysis of long-term effects of stabilization policies.
\end{abstract}

Keywords: Business cycle; long-term growth; stabilization policy; agent-based model JEL Classification: C63, E32, O33

\section{Introduction}

The recent world economic crisis marks the deepest downturn in the postwar era. Triggered by the subprime mortgage crisis in the United States that evolved into a world financial liquidity crisis, the recession affected the entire world economy, with greater detriment to some countries than others. According to OECD statistics, the U.S. economy declined by $3.5 \%$ from the first quarter in 2008 to the second quarter in 2009, whereas Japan recorded a contraction of $8.0 \%$ in the same period. In the area of the European monetary union, economic activity fell by $5.1 \%$ and in Germany as the biggest economy in the Euro area, the GDP declined by $6.3 \%$ (see OECD, 2010b). This severe economic contraction forced many governments to take appropriate countermeasures. Looking back, discretionary fiscal policies can be identified as a central tool applied to counteract the recession. In fact, the U.S. administration enacted economic stimulus packages in the years 2008 and 2009 accounting for $5.6 \%$ of the GDP in 2008. For Japan and Germany, the relative sizes of the economic recovery plans were lower but with $4.7 \%$ for Japan and $3.2 \%$ for Germany still remarkable (see OECD, 2010a).

Stabilization policies that aim at alleviating the effects of economic downturns have been the focus of a passionate decades-long dispute in macroeconomics that yet remains to be resolved. For a long time, the central question had been whether stabilization policies

\footnotetext{
*Financial support of the German Science Foundation (Collaborative Research Center (SFB) 882 'From Heterogeneities to Inequalities') is gratefully acknowledged.

${ }^{\dagger}$ Department for Business Administration and Economics,Bielefeld University, Germany
} 
are at all effective tools to smooth business cycles. The endogenous growth theory and its implication that any type of shock - be it temporary or permanent, real or nominal can have permanent effects in the long run opened a new perspective: the link between short-term volatility and long-term growth. Inspired by this new perspective, a strand of the subsequent growth literature dealt with the question of whether stabilization policies will reduce or enhance long-term growth. A drawback of a large part of this literature is, however, that it has paid less attention at incorporating a concrete stabilization policy in order to check whether the policy itself introduces implications for long-term growth. Instead, conclusions regarding the connection between stabilization policies and long-term growth have solely been derived from considering the link between short-term volatility and long-term growth. And in the sparse attempts that have explicitly accounted for stabilization policies, the explanation of the direction of possible long-term effects of stabilization policies has been focused on either the modeling approach of endogenous technological change or the source of shocks driving the short-term volatility.

The concern of this paper is the important, but largely neglected, question whether the design of fiscal stabilization policies matters for the long-term effects of the policies. We use a closed agent-based macroeconomic model that generates endogenous business cycles in order to show that alternative fiscal policies can have different implications for long-term growth. More precisely, we run policy experiments in which three distinct fiscal policy measures are applied to mitigate the amplitude of the business cycle. The first policy provides consumption subsidies to households and the two other policies provide investment subsidies to firms. The difference between the investment subsidies is that the one policy subsidizes any investment in the physical capital stock of firms and the other only those that flow in the most up-to-date technology. We can show that all policies are equally effective in smoothing business cycles but differ substantially in their implications for longterm growth. In particular, the technology subsidy is associated with a strong positive effect on long-term growth while the consumption subsidy leads only to a weak positive effect. And the investment subsidy has even a negative effect on the growth rate.

The paper is organized as follows: Section 2 provides a literature review of stabilization policies and long-term growth. Section 3 lays out the model and reports some generic properties of simulation outcome generated with the model. Section 4 contains the analysis of the three stabilization policies. Section 5 concludes.

\section{Stabilization Policies and Long-term Growth in the Literature}

The importance of discretionary fiscal policies during the economic crisis does not correspond with the role that fiscal policy has recently played in contemporary macroeconomics. From a historical perspective, fiscal policy had been the central macroeconomic tool in the aftermath of the Great Depression and the following era of Keynesian macroeconomics (see Blanchard et al., 2010). But over the decades, the focus has moved from fiscal to monetary policy and in the past two decades fiscal policy has clearly taken a backseat (e.g., Eichenbaum, 1997). There are manifold possible reasons for the declining importance of fiscal policy. One is certainly the general skepticism regarding the effectiveness of fiscal policy as stressed by the New Classical school (e.g., Lucas and Sargent, 1979). Another reason concerns problems of time lags in detecting recessions and the implementation of policies as well as issues related to the political economy. A third possible explanation is related to the Great Moderation, which is the empirically observed phenomenon of a substantial reduction in the volatility of U.S. business cycle fluctuations starting in the mid-1980s (Blanchard and Simon, 2001; Stock and Watson, 2003). Some studies such as Summers (2005) have shown that an improved monetary policy can explain the emergence of the moderation. But if there is already an effective policy to stabilize the business cycle, then there is no need for another policy instrument such as fiscal policies. The question remains, however, why governments have used fiscal policies so extensively during the crisis. Blanchard et al. (2010) argue that monetary policy, including quantitative easing and credit, had largely reached the limits with the result that policymakers had little choice but to rely on fiscal policy. Furthermore, 
fiscal stimulus measures had generally been more accepted by policymakers even before the crises and had been used in many instances, not only as a response to severe shocks.

Until the 1980s, short-term fluctuations and long-term economic growth had been considered as two coexisting and independent phenomena by most mainstream macroeconomists, leading to a major divide in macroeconomic theory. On the one side, business cycle theorists had considered long-term growth as an exogenous trend and analyzed the cyclical component by typically using Keynesian macroeconomic models. On the other side, growth theorists had typically used Neoclassical growth models to analyze the trend component, where shortterm shocks had no impact on the long-term growth rate of the economy (e.g., Martin and Rogers, 2000; Gaggl and Steindl, 2008). Stabilization policies that aim at smoothing the business cycles had then been analyzed in the context of short-term models neglecting any possible effect on the long-term growth rate. This traditional dichotomy eroded when Nelson and Plosser (1982) found empirical evidence showing that long historical U.S. time series data could be characterized by non-stationary processes that have no tendency to return to a deterministic path. When decomposing the time series in a secular and a cyclical component, shocks to the secular component would substantially contribute to the variation in observed output. As a consequence, Nelson and Plosser (1982) questioned the general separation of business cycle and growth theory.

Real Business Cycle (RBC) and New Keynesian models, which represent the predominating branches in macroeconomic theory within the 1980s and 1990s, were the first models incorporating business cycles and long-term growth in a unified framework. Modern mainstream macroeconomics combines elements of both approaches with the result that the major workhorse in contemporary macroeconomics are models that feature the structure of RBC models and inherited nominal rigidities from New Keynesian models (e.g., Woodford, 2009). In any case, the line of research that has applied models with RBC and/or New Keynesian features is basically interested in replicating business cycles and analyzing transient effects of shocks on macroeconomic aggregates. The determination of long-run growth is not the question of this research per se (Gaggl and Steindl, 2008). Since the steady state growth is exogenous by construction, these models cannot account for a causal relationship between short-term volatility and long-term growth as evidenced by Nelson and Plosser (1982).

The endogenous growth literature has tried to fill this gap. In a typical endogenous growth model, the process of technological change as the main driver of long-term growth has endogenous determinants including investments in human capital and research and development. Some of these determinants are influenced by the volatility of the business cycle, which provides a connection between short-term fluctuations and long-term growth. In that sense, endogenous technological progress acts as a propagation mechanism for shocks that would only have transitory effects in a New Keynesian or RBC framework (Stadler, 1990).

The endogenous growth literature provides an ambiguous answer to the question of the relationship between (the smoothing of) cyclical fluctuations and long-term growth. In this context, two contrasting explanatory paradigms can be identified, reflecting two different approaches for the modeling of endogenous technological change: the one following Schumpeter's concept of creative destruction and the other based on the learning-by-doing hypothesis (see Priesmeier and Stähler, 2011).

In models following the creative destruction hypothesis, one can typically find a positive link between short-term fluctuations and long-term growth. This positive effect emerges as recessions have a positive effect on the long-term productivity level of the economy. There are basically two explanations for this positive relation. The first describes a cleansing effect of recessions (Caballero and Hammour, 1994), through which unproductive firms that lack competitiveness are driven out of the market. As a consequence, the overall productivity of the economy will be higher when the economy recovers. The second explanation, used by e.g. Aghion and Saint-Paul (1998), stresses the importance of procyclical opportunity costs for productivity-enhancing activities. Activities such as research and development, training, and implementation of new technologies are costly in terms of forgone current production (Saint-Paul, 1997). This is because these activities tie up production capacities that are not available for production. Therefore, in a recession when output is currently low, the cost of such activities is low relative to their benefit, which includes increased production in the future when the economy is back to an expansionary phase. 
In any case, the assumption of creative destruction being the main driver of endogenous technological change implies a trade-off between short-term volatility reduction and longterm growth. If the policy reduces the business cycle and therefore prevents the economy to fall into recession, then it will also suppress the cleansing mechanism or, respectively, the reduction of opportunity costs. As a result, the speed of technological change will eventually fall. This implies a conflict of goals so that a government must sacrifice long-term growth for achieving short-term stability.

Aghion et al. (2005) show that the opportunity cost argument is only valid if credit markets are perfect. If credit markets are sufficiently imperfect, then productivity-enhancing investments become procyclical and a reduction of the volatility would lead to higher growth. In this scenario, the goals of short-term stabilization and long-term growth are not conflicting any more. This finding is consistent with the results one typically obtains when considering the alternative explanatory paradigm for endogenous technological change, the learning-bydoing hypothesis. In models of this type as, e.g., Stadler (1990), Martin and Rogers (1997, 2000), the propagation mechanism is assumed to emerge through an endogenous formation of human capital. Stadler (1990) describes the learning process as a by-product of production in which workers build up skills and experiences during their employment. Since labor can freely move between firms, the generated skills become an externality and constitute to a common stock of technical knowledge. Periods during a negative output shock, when output and employment are low, are forgone opportunities for learning-by-doing and have a negative effect on the accumulation of human capital. If the employment is increasing and concave in the business cycle disturbance, the forgone learning cannot be fully regained over the next upswing (Martin and Rogers, 2000). Then, a transitory shock translates in a permanent effect on the long-term growth path of the economy. In this case, a stabilization policy counteracting a negative shock will have an enhancing effect on long-term growth.

But the picture is also not unambiguous for models based on the learning-by-doing hypothesis. Blackburn (1999), for example, shows that it depends on the concrete specification of the human capital accumulation function, i.e. the technology underlying the learning process, to determine whether growth and volatility are positively related. And Blackburn and Pelloni (2004) emphasize the source of the fluctuation. Their analysis of a monetary growth model with nominal rigidities and learning-by-doing predicts that the relationship between output growth and output volatility may be positive or negative according to whether real or nominal shocks predominate.

The focus of most endogenous growth models has been on the relation of short-term volatility on long-term growth, from which possible effects of stabilization policies are derived as a corollary. This, however, does not include issues of formulation and evaluation of stabilization policies, a point that has to some extent been neglected in the literature. Blackburn (1999) and Blackburn and Pelloni (2005) consider monetary stabilization policies governed by feedback rules. While the former finds a negative effect on long-term growth, the latter find that the monetary stabilization policy may work either for or against the promotion of long-term growth depending on the source of the fluctuations. Martin and Rogers (1997) develop a model in which learning-by-doing is at the origin of growth and analyze the effects of a fiscal stabilization policy that subsidizes labor during bad periods and taxes in good times. They find that in many configurations of disturbances and model parameters, the countercyclical tax policy can have positive effects on long-term growth by minimizing the adverse effects that recessions have on learning-by-doing. These examples illustrate that mostly structural aspects have been emphasized in the few investigations that incorporate a concrete stabilization policy. These structural aspects include the specification of the learning function (Blackburn, 1999), the nature of the shocks (Blackburn and Pelloni, 2005), and structural parameters controlling the severity of shocks, their likelihood to occur, and the speed of learning (Martin and Rogers, 1997). But no emphasis has been put on investigating the question whether different (fiscal) policies, which all aim at stabilizing the business cycle, can have different implications for the long-term growth path. 


\section{The Model}

\subsection{General Considerations}

The aim of this paper is to address the question of possible links between different shortterm stabilization policies and long-term growth by means of an agent-based policy analysis. The choice of the agent-based approach is backed up by generic properties of this approach, which make it particularly suitable for the analysis of economic policies. One of these characteristics is the flexible nature stemming from the fact that agent-based modeling is freed from taking account of analytical tractability. The high degree of flexibility allows adjusting the comprehensiveness of agent-based models to the macroeconomic phenomenon under study (see LeBaron and Tesfatsion, 2008), which facilitates the development of models with the necessary depth and complexity required for a thorough analysis of the policy question at hand. Another strength of the approach stemming from its flexibility is that it enables incorporating different policies in a unified model framework. This makes a comparative analysis of different economic policies under identical laboratory conditions possible in the first place.

Agent-based modeling is a disequilibrium approach considering the evolution of complex adaptive systems from the bottom-up. The emerging out-of-equilibrium dynamics enable a policy analysis on different time scales, where policy effects can typically be distinguished in short- and long-term effects (see Dawid and Neugart, 2011). Considering different time scales is especially useful in the context of short- and long-term effects of stabilization policies. Furthermore, the bottom-up approach allows to explain the policy effects as the emerging outcome of mechanisms interacting at the micro level.

The analysis is conducted with an extended version of the agent-based macro model Eurace@Unibi. The original model has especially been used for policy analyses in the context of regional convergence (e.g., Dawid et al., 2012a, 2014). One interesting property of this model is its ability to generate endogenous business cycles with economically reasonable characteristics. This makes the model suitable for the discussion of policies aiming at smoothing the business cycle and offers a strong contrast to most dynamic equilibrium models, in which exogenous stochastic shocks are the source of short-term fluctuations. The fact that equilibrium models need exogenous shocks in order to introduce business cycles has been criticized by, e.g., Dosi et al. (2006).

In the last ten years a number of closed macroeconomic models using an agent-based approach have been developed (e.g., Gintis, 2007, Dosi et al., 2010, Delli Gatti et al., 2010, Ashraf et al., 2011; Raberto et al., 2012; Wolf et al. 2013; Dosi et al., 2013 Riccetti et al., 2013). Several of these agent-based macroeconomic models have shown the importance of the approach for economic policy design. For example, Dosi et al. (2010) look into interaction of policies aiming at the strengthening of demand and of policies facilitating the speed of technological change. Monetary policies are addressed in Ashraf et al. (2012) or Arifovic et al. (2013), whereas regulatory issues relating to credit and financial markets are analyzed by Delli Gatti et al. (2010), Ashraf et al. (2011), Dosi et al. (2013) or Riccetti et al. (2013) within agent-based macroeconomic models.

In the following subsections, we provide a description of the agent-based macro model, thereby limiting the description on main aspects of the model that are crucial for the understanding of the results. An extensive description of the Eurace@Unibi model can be found in Dawid et al. (2012b). And a detailed description of the model extensions is provided in Harting (2014).

\subsection{The Overall Structure}

The model describes a market economy in which heterogeneous agents interact on different markets. The agents populating the economy are households, firms, where we distinguish consumption and capital goods producing firms, and banks. Additionally, there is a central bank and a government, where the latter collects taxes and finances social benefits.

The focus of our analysis is on the real sector of the economy including a consumption goods market, a capital goods market and a labor market. At the market for consumption goods, firms produce a homogeneous consumption good that is sold at a central market 
place called outlet mall. Households are consumers and they purchase the consumption good when visiting the outlet mall several times per month.

For the production of the consumption good, firms require labor and capital as inputs which they can purchase at the corresponding factor markets. A monopolistic capital goods firm produces vertically differentiated capital goods and offers several vintages of the capital good at a time. The vintages differ with respect to productivity. From time to time, the capital goods firm carries out a successful innovation and introduces a new vintage with an improved quality onto the market. Thus, technological change is embodied as innovations diffuse into the economy through capital goods investments.

The labor market is populated with workers that have either high or low general skills. Moreover, workers build up technology specific skills on the job. A crucial assumption is hereby that the specific skills of workers and the productivity of machines are linked in a complementary way. This implies that better technologies can only be efficiently used when workers have already acquired sufficient specific skills. Firms adjust the workforce according to their labor demand where the labor market interactions are modeled as a search and matching process.

Households earn a labor income or, if unemployed, they receive unemployment benefits from the government. Moreover, since households are shareholders of firms, they receive dividends. Based on the monthly income and driven by precautionary motives, households determine once a month how much of the income they will spend for consumption.

Consumption goods firms retain parts of their profits as a cash reserve or for financing capital investments. As an alternative financing source, firms can obtain external financing at a credit market. Credits are provided by commercial banks which collect deposits of firms and households. Whether a loan is accepted and how much interests the firm has to pay depends on its financial standing. However, the ability to provide credits is limited by regulations regarding capital requirements and cash reserves.

Firms that are not able to pay their financial commitments declare illiquidity. If debts exceed wealth at the end of the production cycle, a firm has to declare insolvency. In both cases, a bankrupt firm is liquidated after stopping production and dismissing all employees. On the other side, new firms enter the market incidentally starting from scratch only endowed with an initial stock of cash that is provided by a venture capitalist.

The financial sector is completed by a financial market at which agents can trade shares of a single asset. This asset is an index bond that contains all firms and banks of the economy. The total sum of dividends paid out by all firms is distributed among households according to the number of shares a household owns. The central bank provides standing facilities for the banks at a given base rate, pays interest on banks' overnight deposits and might provide fiat money to the government.

Finally, there is a statistical office (Eurostat) that collects data from all individual agents in the economy and generates aggregate indicators according to standard procedures. These indicators are distributed to the agents in the economy which might use them as input for their decision rules.

The agents are characterized by bounded rationality, i.e., agents are limited to information they have and agents cannot fully observe all the consequences of their own actions and that of other agents. This requires the formulation of explicit rules describing how agents build expectations and how they take their decisions based on the available information. In our model, this is captured by modeling the decision-making of agents using a rule-based approach; rule-based means that agents of the same type have an identical set of behavioral rules, each specifically designed for solving a particular decision problem. The design of the decision rules is based on a systematic attempt to incorporate empirically observable behavior documented in the relevant literature. Concerning households, this means that the saving rule and purchasing choice are described by using models from the Marketing literature with strong empirical support. With respect to firm behavior, we follow the Management Science approach, which aims at implementing decision rules and heuristics that match standard procedures of real world firms as described in the corresponding Management literature. A more extensive discussion of the Management Science approach can be found in Dawid and Harting (2012).

Agent actions can be time-driven or event-based, where the former can follow either 
subjective or objective time schedules. Furthermore, the economic activities follow a hierarchy of time-scales: yearly, monthly, weekly and daily activities, all taking place following calendar-time or subjective agent-time. Agents are activated asynchronously according to their subjective time schedules that are anchored on an individual activation day. These activation days are uniformly randomly distributed among the agents at the start of the simulation, but may change endogenously (e.g., when a household gets re-employed, its subjective month gets synchronized with the activation day of its employer due to wage payments). This modeling approach is supposed to capture the decentralized and typically asynchronous nature of decision-making processes and activities of economic agents.

\subsection{Skill Dynamics}

We assume that workers are characterized by two dimensions of human capital endowments. The first dimension is the general skill level and can be interpreted as the formal qualification and those abilities that a worker has obtained during schooling and professional education. There are two skill groups $b_{h}^{\text {gen }} \in\{1,2\}$ with $b_{h}^{\text {gen }}$ referring to the general skill level of worker $h$. The two groups represent low and high levels of general skills, where workers from skill group 1 belong to the low-skill group and those with skill level 2 to the high-skill group.

Specific skills are the second dimension of human capital. They are technology related and are measured in terms of productivity. They can be interpreted as competences and the experience a worker has collected while working with a certain production technology. The underlying assumption of learning-by-doing is thereby supported by empirical evidences. Bahk and Gort (1993), e.g., found a significant effect of learning-by-doing on output of 15 industries, where the learning appeared to be uniquely related to embodied technological change of physical capital.

The learning process and hence the speed of acquiring specific skills is assumed to be depending on the general skill level of the worker. Suppose the machines used by $h$ 's employer $i$ at time $t$ have an average productivity of $A_{i t}$, then the specific skills of worker $h$ evolve according to

$$
b_{h t+1}=b_{h t}+\chi\left(b_{h}^{g e n}\right) \cdot \max \left[0, A_{i t}-b_{h t}\right] .
$$

The function $\chi$ is thereby increasing in $b^{g e n}$. Note that we assume that the generation of new technologies is a cumulative process. This implies that specific skills are transferable between vintages, even from old to new technologies. Furthermore, we assume that general skills are observable by firms in the hiring process while specific skills are not. But specific skills become observable ex post during the production process.

The accumulation of human capital within firms and the allocation of human capital among firms is modeled in an explicit microfounded way. As the productivity of workers is determined through learning-by-doing, the model shares a common feature with the strand of learning-by-doing models in the endogenous growth literature. However, the learning takes place at the individual level, i.e. single workers build up skills for the technology they are currently using at the workplace. Since workers can switch jobs via an explicitly modeled labor market, the knowledge transfer between firms in form of spillovers is endogenized and takes place at the disaggregated firm level. This goes beyond the assumption of endogenous growth models that assume perfectly externalized knowledge spillovers (e.g., Stadler, 1990).

\subsection{The Consumption Goods Firm}

\subsubsection{Production Planning}

Consumption good firms use labor and physical capital as input factors in the production process. The capital stock of a firm is composed of different vintages of the capital good. It depreciates over time and increases through investments such that the accumulation of capital of a vintage $v$ follows the law of motion

$$
K_{i t}^{v}=(1-\delta) \cdot K_{i t-1}^{v}+I_{i t}^{v}
$$

The parameter $\delta$ is the depreciation rate and $I_{i t}^{v}$ is the investment in vintage $v$. Technology is embodied in the capital stock and characterized by vintage specific productivity levels $A^{v}$. 
The production technology is represented by a Leontief production function such that labor and capital are used in a complementary way. Moreover, there is a complementarity between the productivity of a vintage $v$ and the average specific skills level $B_{i t}$ of the workforce of the firm. This implies that a vintage cannot be used at its full productivity as long as the workers have not acquired a sufficient level of specific skills.

Given the capital stock and the number of workers $L_{i t}$, the produced output can be computed according to the production function

$$
Q_{i t}=\sum_{v=1}^{V_{t}} \min \left[K_{i t}^{v}, \max \left[0, L_{i t}-\sum_{k=v+1}^{V_{t}} K_{i t}^{k}\right]\right] \cdot \min \left[A^{v}, B_{i t}\right] .
$$

The output $Q_{i t}$ is sent to the mall where it is added to the inventory stock and supplied to households.

The demand for the product of a firm is stochastic. In the Management science literature there are standard heuristics for production planning problems facing stochastic demand. A simple heuristic prescribes to generate an estimation of the distribution of demand and to supply a quantity that is sufficient to fully serve the emerging demand at a probability $\chi^{S}$. The converse probability $1-\chi^{S}$ is then the stock-out probability (which is influenced by stock-out costs, inventory costs and the risk attitude of the firm, e.g., Silver et al., 1998). The target supply is determined by the expected value of the demand $\hat{D}$ and a buffer $\Psi$ that depends on the expected volatility of the demand $\sigma_{D}^{2}$ and the accepted stock-out probability $1-\chi^{S}$. Assuming a normally distributed demand, the buffer is determined according to

$$
\hat{\Psi}_{i t}=\hat{D}_{i t} \cdot q_{\chi^{S}} \cdot \sqrt{\sigma_{D}^{2}}
$$

where $q_{\chi^{S}}$ is the $\chi^{S}$-quantile of the normal distribution; $\sigma_{D}^{2}$ and $\chi^{S}$ are exogenous model parameters.

The planned output is then the difference of that target supply and the current inventory stock at the mall $S_{i t-1}$. However, the output is limited by $\bar{Q}$, which is the feasible output that can at most be produced with the current capital stock. Altogether, the planned output is

$$
\tilde{Q}_{i t}=\min \left[\bar{Q}_{i t}, \hat{D}_{i t}+\Psi_{i t}-S_{i t-1}\right]
$$

\subsubsection{Demand Estimation}

The demand expectation $\hat{D}$ is derived from an estimation procedure that aims at devising a closed form expression translating observed and unobserved but estimated determinants of demand into an expected value. The derivation of this demand function is decomposed in two steps. The first step describes an estimation of the overall development of the consumption goods market represented by the growth of the market size. The market size is given by the overall budget of households disposed for consumption. We assume that firms can ex post observe the aggregated consumption budget. They use previous realizations to predict the market development by estimating an expected growth rate $\hat{g}$.

In the second step of the procedure, the firm estimates how much of the total demand is allocated it. More precisely, the firm estimates the choice probability of a representative consumer regarding its product and uses this probability as a proxy for its market share. The estimation is based on simulated purchase surveys for which the firm draws a representative sample of households. Then, it presents all households a set of different goods at different prices and asks the participating households to simulate their purchase decision on this set of goods. Based on the outcome of this simulation, the firm estimates a discrete choice model that incorporates the prices of the presented goods as an explicit determinant for the purchasing decision. As a result, the firm obtains an estimator for the price sensitivity of households, which can then be plugged in a discrete choice model incorporating the actual range of goods provided at the consumption goods market. By using (expectations of) the prices of its competitors, the firm can compute its expected market share from the choice model. 


\subsubsection{Pricing}

The estimated demand $\hat{D}$ depends on the price that is set before the firm decides the production plan. The price setting of consumption goods firms is based on an elaborate analysis of potential profits. Therefore, the firm defines a set of candidate prices $\tilde{\mathbf{P}}$ that is drawn from an interval around its previous price $p_{i t-1}$. Based on the demand estimation, the firm estimates revenues and costs for the upcoming production cycle associated with each candidate price and selects that price with the highest potential profits. Thus, the firm seeks the profit maximizing price taking into account the trade-off between price, sales and costs.

After the determination of the price and the target output, the firm determines the labor demand and the financial needs. The production plan might induce the need to hire new labor or to obtain additional credits, where there is the possibility that firms are rationed on the labor or credit market. In both cases, output and prices are adjusted accordingly.

\subsubsection{Investment Decision}

Disconnected from the production planning is the capital investment decision, which is taken before the firm enters the production planning. In the financial planning, however, both, the production plan and the investment plan, are considered and, in case of credit rationing, the investment is revised and adjusted first.

The investment decision is based on an appraisal of whether long-term capital investments are worth the funding of cash. That means the firm evaluates the different investment options systematically by checking whether an investment is potentially profitable over a planning horizon.

Firms can purchase different vintages of the capital good at the capital goods market that are distinguished by their embodied productivity and the market price. For this reason, the investment decision is not only to decide on the quantity but also in which vintage of the capital good the firm should invest. This endogenous vintage choice allows incorporating an aspect that has yet received less attention in the integrated business cycles and growth literature, the process of technological diffusion. While technological shocks are the main source of fluctuations in several models of the RBC, New Keynesian and endogenous growth literature, Blanchard (2008) argues that technological progress is a smooth process as it is about the diffusion and implementation of new ideas. Comin (2009) shows in a theoretical framework that the diffusion process amplifies the business cycle and that temporary fluctuations in the intensity of adoption will have persistent effects on the productivity. Our model accounts for a possible propagation mechanism through technological diffusion.

We assume that the decision-making is a three step process. In the first step, the firm appraises different investment strategies and preselects the most profitable one. Therefore, it computes the net present value of the candidate strategies over a planning horizon of length $T^{L T}$, where the firm has to form expectations on the development of the market, the prices of competitors and its own cost structure over the planning horizon. Given the required expenditures for the best strategy and the current financial situation, the firm checks in the second step whether it has to raise additional credits to finance the project. If external financing is needed, the firm assesses the impact on its financial stability. If it turns out that the investment risks the financial standing, then the project is abandoned. The third step takes account of the fact that timing of investments can also matter. A capital investment is an opportunity that can either be executed today or postponed to a later date. But, due to its irreversibility, once it has been committed it cannot be recovered. In those cases, deferring can yield additional value because the economic environment can change in the meantime and so might the estimated value when reevaluating the project after the arrival of new information. If a project is postponed and later it turns out that the value has not changed or has even increased, the firm has still the opportunity to carry out the investment. But if it turns out to be a poor investment, the deferring strategy has preserved the firm to make possible losses. However, by waiting and not carrying out the investment immediately, the firm can also make losses in the form of foregone profits. The value of the waiting option is thereby determined by applying a capital a budgeting model based on the real option approach as described by Benaroch and Kauffman (1999). The investment is 
finally executed if the forgone expected profits exceed the additional value of waiting.

\subsection{Technological Change}

Technological change is modeled in form of embodied technological change as described e.g. by Greenwood et al. (1997). The quality of capital goods is permanently improved through innovations. Productivity gains can be achieved by using capital for production whose productivity is higher than the productivity of the pre-existing capital stock. But due to the inertia of the complementary specific skills, purchasing better capital does not immediately lead to productivity gains (see Section 3.3).

Since the focus of our analysis lies on the interactions of the dynamics of labor and consumption goods markets, the capital good sector is modeled in a simplified stylized way. There is a monopolistic capital goods producer that supplies different vintages of the capital good. A vintage $v$ is characterized by its productivity $A^{v}$ and supplied at infinite supply at a price $p_{I t}^{v}$.

The capital good can be produced and delivered immediately without input factor requirements and consequently without production costs. In order to close the model the revenues are channeled back into the economy by distributing them to households as dividends.

The development of new vintages with an improved quality is assumed to be a stochastic process. At the beginning of month $t$, the development of a new vintage is accomplished at an exogenously given and memoryless probability $\operatorname{prob}^{I n n o}$. In case of a successful innovation, the new vintage becomes the best practice technology where its productivity $A^{V}$ increases compared to the former best practice $A^{V-1}$ by

$$
A^{V}=\left(1+\Delta q^{i n v}\right) \cdot A^{V-1},
$$

with being $\Delta q^{i n v}$ exogenously given and $\Delta q^{i n v}>0$.

The pricing of the vintages is modeled as a combination of cost-based and value-based pricing. Although there are no actual costs in the production process of capital goods, we assume as-if costs that the capital goods firm takes into account. The production of a unit of the capital good, regardless of which vintage, is associated with unit $\operatorname{costs} c_{t}^{C}$. To account for the cost dynamics, we assume that the main factor of production costs is the wage bill. Since wages increase approximately with the same rate as productivity grows, the growth rate of productivity is used as a proxy for the increase in production costs of the capital goods.

Furthermore, we assume that the capital goods firm can observe certain characteristics of its customers and it has certain knowledge of how clients decide on the investment. Moreover, it receives the same market signals as consumption goods firms such that it can estimate the development of the consumption goods market. The capital goods firm uses this information to estimate the average value $V_{t}^{v}$ of one unit of each vintage $v$ for a reference firm whose characteristics, i.e. the set of variables as mean specific skills, average wage etc., match the observed average values of capital good firm's recent clients. Therefore, it computes the present value of additional profits that the reference firm could generate if its capital stock is expanded by one unit of vintage $v$. The additional profit is thereby estimated by an analogue procedure as the consumption goods producer's pre-selection of investment strategies.

As a general rule, the price is set at the level corresponding to the estimated value of the vintage. This follows from the assumption that the capital goods firm interprets the value $V_{t}^{v}$ as costumers' average willingness to pay. There is, however, one exception for which the firm deviates from this rule. It occurs when the value $V_{t}^{v}$ is below the cost level $c_{t}^{C}$. In this case, the vintage is not offered in $t$. It might be the case that all values of the vintages are below $c_{t}^{C}$, though. Then, only the best practice technology is supplied at a price corresponding to the unit $\operatorname{costs} c_{t}^{C}$.

Altogether, we can write the price setting rule as

$$
p_{I t}^{v}= \begin{cases}0, & \text { if } v<\check{v} \text { and } V_{t}^{v}<c_{t}^{C}, \\ V_{t}^{v}, & \text { if } v \leq \check{v} \text { and } V_{t}^{v} \geq c_{t}^{C}, \\ c_{t}^{C}, & \text { if } v=\check{v} \text { and } V_{t}^{v}<c_{t}^{C},\end{cases}
$$


where $\check{v}$ denotes the best practice technology.

There are two implications of this price setting rule. First, the capital goods firm realizes that out of date vintages, i.e. those vintages with productivity significantly below the average productivity of costumers' capital stock and workforce, do not have any value for its clients. Consequently, those vintages are withdrawn from the market. Second, capital goods prices react to changes of expectations of consumption goods firms concerning the market performance. As a consequence, prices might be higher in prospering and lower in economically bad times.

\subsection{Labor Market Interaction}

Based on the planned output and the available financial resources, consumption goods producers determine the labor demand $\tilde{L}_{i t}$ for the current production cycle $t$. If the workforce employed at the beginning of $t$ is not sufficient to cover the required labor demand, firms enter the labor market in order to recruit new employees. Therefore, they post vacancies that can be read by job searchers.

The wage offer plays an important role in the hiring process. In an ideal world firms would pay workers an individual wage that perfectly matches the productivity level of each worker. But as the productivity of applicants is assumed to be unobservable, they cannot directly link the wage to the individual productivity. What firms can, however, observe is the general skill level of applicants. Furthermore, they can monitor the productivity of the incumbent workforce in total and the averages for the two general skill groups separately. By interpreting the general skill level $g$ as a signal for the productivity, firms expect the specific skills of applicants to be at the average level $\bar{B}_{i g t-1}$ of incumbent workers belonging to the same skill group as the applicants do. For each general skill group $g$, firms post a separate wage offer $w_{i g t}^{O}$ that is determined according to

$$
w_{i g t}^{O}=w_{i t}^{b a s e} \cdot \min \left[A_{i t}, \bar{B}_{i g t-1}\right] .
$$

The first factor $w_{i t}^{\text {base }}$ of the right-hand site represents a market driven base wage offer that is paid per unit of specific skills. The second factor is the effective productivity that a new worker is expected to yield. Effective productivity means that, due to the assumed complementarity, high specific skills cannot be fully utilized if the capital stock does not have a sufficient productivity, i.e. $A_{i t} \geq \bar{B}_{i g t-1}$. In those cases, firms are unwilling to pay wages that correspond to their actual labor productivity and limit the wage offers accordingly.

Unemployed workers accept only those job offers whose salary exceeds a reservation wage $w_{h t}^{R}$. When becoming unemployed, the reservation wage is set at the level of the last earned wage and, as long as the household cannot find a new job, it declines over time by

$$
w_{h t+1}^{R}=(1-\psi) \cdot w_{h t}^{R} .
$$

Note that the reservation wage cannot fall below the level of unemployment benefits, which itself is a fraction $u$ of the last labor income.

The labor market interaction between households and firms is described by a simple two-round search-and-matching algorithm. In the first step, firms post vacancy notifications that can be read by unemployed households. Job seekers consider the posted wages $w_{i g t}^{O}$ for the skill group they belong to and send applications for those jobs whose wage offers exceed the reservation wage. The number of applications per workers is thereby limited. In the next step, firms collect all applications and decide based on a logit discrete choice model which applicants to send a job offer. A parameter $\gamma^{g e n}$ of the logit model specifies the weight that general skills have in the decision process. Finally, households getting one or more job offers become re-employed, where households with more than one offer accept that one associated with the highest wage and reject the others. Thus, it is not ensured that firms can fill all vacancies. At the same time, there might also be households that have not received any job offers.

Both, rationed firms and households, have a second opportunity to be matched in a second round of the labor market procedure. Before reentering the labor market, the rationed firms increase their base wage offer $w_{i t}^{\text {base }}$ by

$$
w_{i t}^{\text {base }}=(1+\varphi) \cdot w_{i t}^{\text {base }} .
$$


This should account for the fact that firms that have failed to fill vacancies try to attract new workers by raising their wages.

In the opposite case, when the labor demand is lower than the number of workers employed at the beginning of $t$, firms have to make redundancies. They expect that high-skilled workers have either higher specific skills or, at least, are capable of learning faster while working with more productive technologies. Therefore, firms dismiss workers with low general skills first. Additionally, there is a small probability for each worker-employer match to be separated in each period. This should capture job separation due to reasons not explicitly captured in the model.

Not only the wage of new workers but also the wage of the incumbent workforce is linked to the productivity. By assuming that the wage keeps pace with the productivity growth in the economy, the individual wage of a worker $h$ changes according to

$$
w_{h t}=\left(1+p r_{t-1}\right) \cdot w_{h t-1},
$$

where $p r_{t-1}$ is the average productivity growth achieved in the previous period $t-1$.

\subsection{Consumption Market Interaction}

There is a considerable degree of uncertainty regarding the household's monthly income stemming from two sources. The first source is the labor income that can rapidly change by being fired or hired. The second source of uncertainty is the capital income that depends on fluctuating dividend payments of firms. For a saving and consumption decision with uncertain income, a strand of the consumption theory literature describes models with buffer stock saving in which households undertake precautionary saving in order to preserve them against bad future incomes. This theory is also supported by empirical evidences (e.g., Deaton, 1991; Carroll and Summers, 1991).

For determining the consumption budget, households apply a linear approximation of an optimal buffer stock saving rule as described in Allen and Carrol (2001). The desired buffer stock depends on the current income and is determined by a target ration $\Phi$ of wealth to income. As long as the actual wealth matches the desired buffer, a household would completely spend the monthly income for consumption. In case the actual size of the wealth deviates from the planned buffer, the household reacts by increasing or decreasing the monthly consumption budget relative to the income, depending on the deviation of the wealth from its target. A parameter $\kappa$ indicates how sensitive the consumption reacts on the deviation. The rule can be written as

$$
C_{h t}^{e x p}=I_{h t}+\kappa\left(W_{h t}-\Phi I_{h t}\right),
$$

where $I_{h t}$ is the monthly income consisting of labor or unemployment benefits, respectively, as well as dividend payments. $W_{h t}$ is the wealth consisting of money holdings and asset wealth in shares.

The consumption goods market is represented by a central outlet mall in which consumption goods producers offer and sell their goods to households. Households visit this outlet mall once a week and try to spend the entire weekly budget for one good. The days at which they go to the mall are randomly distributed among households. The customers can observe the prices but they do not get information about the available quantities. The purchasing decision of households is described using a logit model as suggested in the Marketing literature (e.g., Malhotra, 1984). The relative price of goods is an important factor influencing the outcome of the decision, where the intensity of choice with respect to the prices is set by a parameter $\gamma^{C}$.

Since firms have inflexible production cycles they can refill the mall inventories only once per month. Furthermore, the individual delivery dates of firms are asynchronized. Thus, the supply is strictly limited by available inventory stocks and, since the households have no information on the inventories, there is the possibility to be rationed. In this case, the mall sets a rationing quota corresponding to the percentage of the total demand that can be satisfied with the available goods and each household gets the indicated percentage of the requested consumption. Rationed households have a second chance to spend the remaining budget for another good. 


\subsection{Parametrization and Initialization}

The model hosts a considerable number of parameters. In order to determine a parametrization for the simulations, we follow an approach that combines a direct estimation of parameters for which empirical observations are available with an indirect calibration approach. Calibration means we use the degrees of freedom stemming from parameters without empirical counterparts to tweak the model in such a way that it generates economically accurate simulation outcomes. This facilitates the ability of the model to capture economic mechanisms which are relevant for real world economic dynamics. Table 1 provides an overview of the standard constellation of model parameters obtained from the empirically grounded calibration procedure. Table 2 shows the set-up of the model regarding the number of agents of each type, the general skill distribution among households and the adjustment speed of specific skills for the general skill groups. Both tables can be found in A.

Technological change is one of the main drivers of long-term economic growth, where the technological development is mainly determined by the growth of the technological frontier and the diffusion of technologies. To avoid spurious growth effects stemming from stochastic differences in the dynamic of the technological frontier between runs, we use in all considered runs an identical realization of the stochastic process governing the emergence of new vintages.

Agent based models are typically characterized by strong path dependencies. Thus, the initial state of the system, which is an exogenous input to the simulation, can have considerable effects on the simulation output. This makes the choice of the initial state to a crucial one. In general, there are several conditions that constrain the initialization of agents' state variables. First and foremost, the initial values of the variables should be plausible in order to avoid odd initial states generating economically unreasonable simulation outcomes. Second, we have to consider several interdependencies of variables. Especially with respect to the balance sheet of agents, we have to initialize the variables according to the criterion of stock-flow consistency. If the balance sheets are inconsistent from the start, they would remain so throughout the entire simulation. Thus, we are constrained to set the initial values in such a way that the balance sheet relationships between agents hold (a deeper discussion of these constraints can be found in Dawid et al., 2012b).

We set up the model such that the agents are initially homogeneous with respect to most characteristics. Firms have identical assets (a capital stock of the same size and quality, and the same amount of liquidity) and liabilities, and there are no established worker-employer matches. Households own the same wealth and are endowed with the same specific skills. Distributions of these variables among agents evolve endogenously over the simulation. One exception are the general skills of households, which are heterogeneous from the start and distributed according to the distribution reported in Table 2

It should be clear that any initialization has invariably transient effects but these transient effects level off with elapsing simulation time. In order to alleviate that those transient effects distort the policy experiments, we use a start state of the economy for the simulations which is already settled. To obtain this initial condition, we have run a pre-simulation based on the initial state described above and chosen a post-transient snapshot of this simulation as the initialization for the simulations.

\subsection{Business Cycle Properties and Stylized Facts}

A standard approach to build confidence in agent-based models is the empirical validation. In this procedure, one compares data from the model data-generation process (DGP) with empirical data, which can be interpreted as the unique outcome of an unknown real-world data-generation process. If the simplified model DGP replicates a selected set of stylized facts of the empirical data, then the model DGP can be considered as a sufficiently good representation of the real-world DGP (cf. Fagiolo et al., 2007).

In the following, we present some properties of a representative simulation outcome from the model DGP based on the default parametrization and relate them to stylized facts from the literature. Our focus is on the model's ability to generate endogenous business cycles with realistic properties, which can be seen as a strong evidence for the model's applicability to consider business cycle policies. 


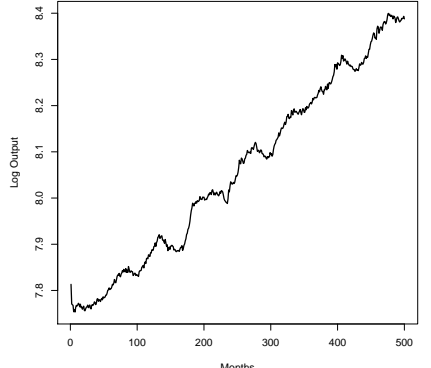

(a)

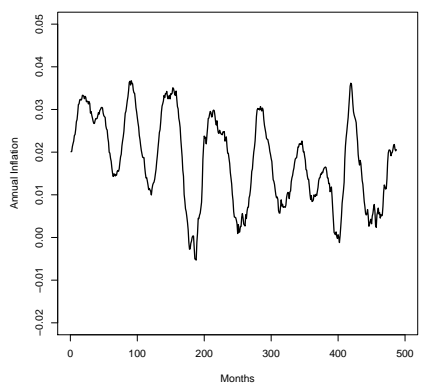

(c)

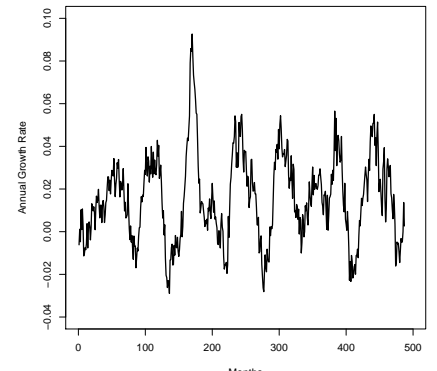

(b)

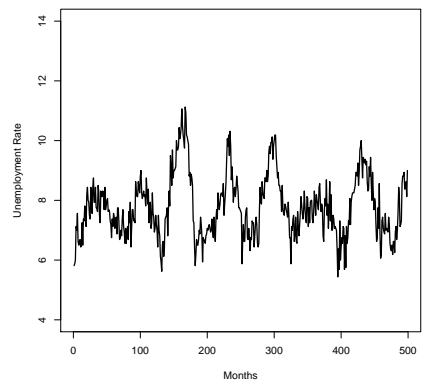

(d)

Figure 1: Time series of (log) output (a), annual growth rate (b), annual inflation rate (c), and unemployment rate $(\mathrm{d})$.

Figure 1 shows the main macro variables output, annual output growth rates, inflation and unemployment rate. Panel (a) and (b) illustrate that the model generates endogenous business cycles. Output dynamics are characterized by persistent fluctuations and persistent growth, i.e. there is a business cycle component around a positive output trend. The longterm annual growth rate is $1.6 \%$ while the growth rate deviates over the business cycle considerably from its long-term average.

The volatility of the business cycle can be measured by computing the percentage standard deviation of the cyclical component. In order to extract the cyclical component, the time series can be detrended by means of the HP filter with $\lambda=1600$, which is a standard choice for a business cycle analysis of quarterly data (e.g., Hodrick and Prescott, 1997). The relative standard deviation is $1.54 \%$, which is close to empirically reported values. Sorensen and Whitta-Jacobsen (2005), for example, report a volatility of $1.66 \%$ for the U.S. business cycle between 1955 and 2001.

High persistence is a further empirical regularity of the business cycle. Persistence describes the dependency of the level of output in period $t$ from its previous realizations and is typically measured by the one-quarter auto-correlation. The auto-correlation coefficient of the cyclical component of output is 0.9 , which implies that the business cycle is highly persistent. This observation is also in accordance with empirical observations; Sorensen and Whitta-Jacobsen (2005), e.g., report a value of 0.86 for the U.S. economy.

The average length of the detected business cycles is about 21 quarters (corresponding to 5.25 years) with a minimum length of 17 quarters and a maximum of 24 quarters. This is within the range of 6 to 32 quarters, which is customarily used for defining business cycles in the empirical literature (e.g., Baxter and King, 1999). Moreover, Figure 1 shows a persistent inflation, fluctuating in a corridor between -0.5 and $4 \%$ with a mean of $1.8 \%$ (panel c). Also the unemployment rate fluctuates, where its range is between 5.5 and $11.2 \%$ with a mean of $7.8 \%$ (panel d).

The empirical business cycle literature examines the relationship between the aggregate business cycle and various other macroeconomic variables, such as prices, wages, employment, productivity, investment, and consumption. A broader discussion of business cycle properties of 71 U.S. economic time series can be found in Stock and Watson (1999). 


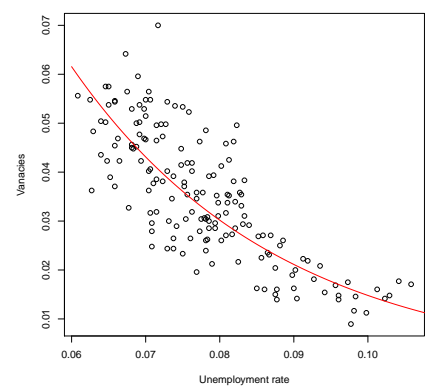

Figure 2: The Beveridge curve approximated by means of a log-linear regression.

Harting (2014) demonstrates for a wide range of variables that the model reproduces the co-movement behavior as described in Stock and Watson (1999): Harting (2014) finds, e.g., pro-cyclical co-movement of consumption, investments, employment, and productivity; counter-cyclical co-movement of prices, wages, and mark-ups. The countercyclical behavior of mark-ups is thereby a particularly interesting feature of the model as, in contrast to most standard macroeconomic models, mark-ups are here determined endogenously at the firm level. It has been argued by Blanchard (2008) that, indeed, there is empirical indication of countercyclical mark-ups and that it is a wide open macroeconomic research question to provide sound theoretical explanations for the movement of mark-ups along the business cycle (see also Bils and Chang, 2000).

Besides the properties of the business cycle, the model can also replicate other stylized facts reported in the literature. Regarding labor market regularities, the relation between the unemployment rate and the vacancies rate is typically shown in the Beveridge curve, where the literature reports a negative correlation between unemployment rates and the vacancy rates (e.g., Blanchard et al., 1989). Figure 2 shows the Beveridge curve generated from the benchmark simulation, which is clearly downward sloping. In fact, the model generates a negative relation between unemployment and vacancies.

The empirical literature on firm size distributions reports a tendency of firm size distributions to be right-skewed with upper tails made of few large firms (e.g., Dosi et al., 2006). Panel (a) of Figure 3 shows the simulated firm size distribution in a Log Rank vs. Log Size plot, where output is used as a proxy for firm size. The actual firm size distribution is represented by circles while the solid line shows the log-normal distribution with the sample mean and standard deviation as distribution parameters. The plot indicates that the firm size distribution is close to the log-normal distribution so that it is characterized by a considerable right-skewness. It should be noted that the firm size distribution in panel (a) is based on a snapshot of the simulation at month 250; in panel (b) we present a heat map depicting the evolution of the firm size distribution over time. The color code indicates the density of the output distribution. This panel illustrates that the right-skewness of the distribution is persistent.

Lumpiness of investments at the firm level is a frequently reported regularity for the capital accumulation (see Dosi et al., 2006). Based on U.S. plant level data, Doms and Dunne (1998) show that $51.9 \%$ of plants expand their capital stock by less than $2.5 \%$ in a year, while $11 \%$ of plants increase their capital stock by more than $20 \%$ within the same time interval. In the benchmark simulation, $59 \%$ of firms invest less than $2.5 \%$ within a given year, while $7 \%$ of firms increase their capital stock by more than $20 \%$. However, these $7 \%$ contribute significantly to the aggregated investment as they account for $20 \%$ of the total investments. At the other end of the distribution, the $59 \%$ of firms, which increase the capital stocks by less than $2.5 \%$, contribute to about $22 \%$ of the overall investment. This suggests that, in accordance with empirical evidences, the investment behavior of firms in the model is characterized by a considerable lumpiness.

Finally, the emerging productivity dynamics of firms show some characteristics which are widely described in the literature (see again Dosi et al., 2006). Figure 4 (a) depicts the evolution of the productivity distribution over time where productivity is measured as 


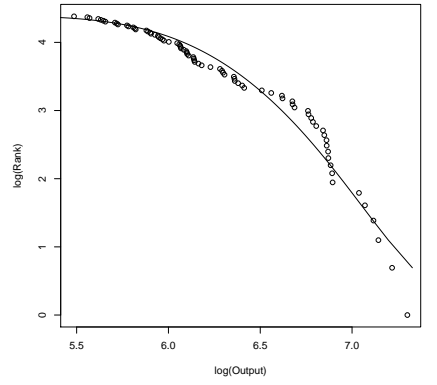

(a)

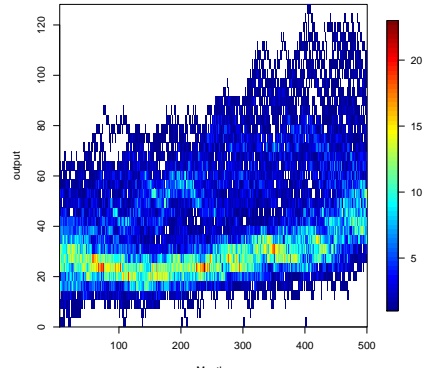

(b)

Figure 3: Firm size distribution; Log Rank vs. Log Size plot of firm output (a) and evolution of output distribution (b). The color code indicates the density of the population distribution in the considered range of the variable output.

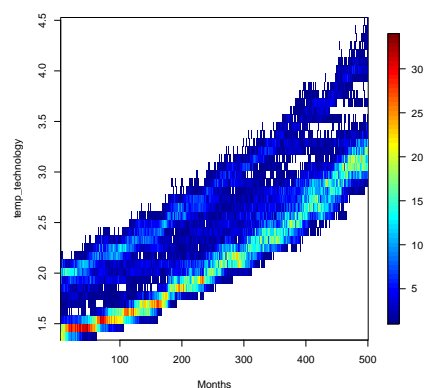

(a)

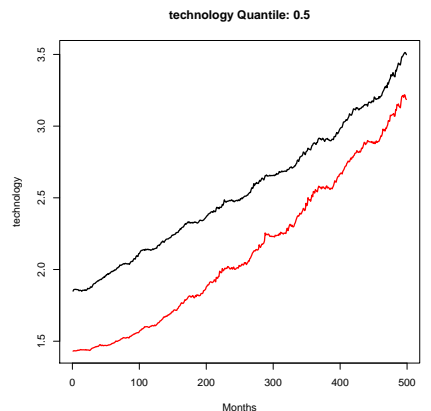

(b)

Figure 4: Evolution of the productivity distribution (a) and evolution of average productivity of firms that are low-productive (red) and high-productive (black) at $t=100$ (b).

the productivity of the utilized capital stock. Besides the general increase of the average productivity due to technological progress, this figure indicates that there is considerable productivity dispersion among firms and the distribution, as that of firm sizes, tends to be right-skewed. Panel (b) indicates a high persistence of productivity differentials between firms, which is a further empirical regularity reported by Dosi et al. (2006). The panel shows the evolution of the average productivity of two subgroups of firms, which belong either to the lower $50 \%$ quantile (red line) or to the upper $50 \%$ quantile (black line) of the technology distribution at months 100. Evidently, there is only little technological catch up of the lagging firms. Firms that have belonged to the group of low-tech firms in an early phase of the simulation show a high probability to remain low-tech throughout the simulation.

\section{The Policy Analysis}

\subsection{Policy Design}

In this section we employ the model for policy experiments in which we investigate the effectiveness of different fiscal policy measures that aim at smoothing the business cycle volatility. The policies analyzed in the experiments are stylized instances of policies that have actually been used by the U.S. government during the Great Recession. In the Economic Stimulus Act of 2008, the U.S. administration of President George W. Bush put together a stabilizing program that consisted of basically three main packages 1 The largest package contained a $\$ 100$ billion tax rebate program for households. Estimates show that these tax rebates led to a stimulus of aggregate demand of 0.5 to $1.0 \%$ in the second quarter of 2008

\footnotetext{
${ }^{1}$ see, e.g., http://www.taxpolicycenter.org/briefing-book/background/stimulus/2008.cfm (accessed on February, 9th, 2015).
} 
and 0.16 to $1.81 \%$ in the third quarter of 2008 (see Broda and Parker, 2012). The other two packages contained business provisions that aimed at encouraging investments by increased limits on expensing investment costs and accelerated depreciation for some investments. According to estimations of the U.S. Congress, the investment enhancing policy reduced the tax revenue by $\$ 51$ billion in fiscal 2008 and 2009. Since the claims for depreciation were only brought forward, tax revenues have risen by $\$ 43.5$ billion in the subsequent years; but the net effect might still be $\$ 7.5$ billion. The American Recovery and Reinvestment Act of 2009 was signed into law by President Barack Obama as a follow up program of the Economic Stimulus Act. This package had a total size of $\$ 900$ billion and provided also tax cuts $(\$ 275$ billion) and increased existing programs. But in contrast to its predecessor, some of the measures contained in the American Recovery and Reinvestment Act had a strong focus on encouraging the technological advance of the U.S. economy $\left.\right|^{2}$ Besides expending $\$ 15$ billion directly for scientific facilities and research, it provided over $\$ 30$ billion for investments in renewable energy and smart grid power networks as well as $\$ 7$ billion for expanding broadband internet access. This government money was designated to flow to both, the private sector and directly to federal, state, and local government.

Altogether, the different policy measures of the two packages can be summarized under three distinct policy categories; demand subsidization, investment subsidization, and technology subsidization. We mimic these policies in a highly stylized way and try to address the two following research questions: Are these three policies actually able to smooth the business cycle? And do the policies have long-term effects on the growth path of the economy?

We abstract from problems associated with time lags in detecting recessions and implementing policies as well as from issues of the political economy. The stabilization policies are automatically introduced and adjusted when there is a risk of the economy to plunge into an economic crisis. Therefore, we define a threshold growth rate $g^{t h}$ at which the policy is automatically installed if the quarterly growth rate $g_{t-1}^{Q}$ of the last period is below this threshold ${ }^{3}$ In order to achieve the stabilizing effect, the expansion of the policies are adjusted depending on the deviation of the last-period growth rate from the threshold.

The first considered policy is a classical demand-oriented Keynesian stimulus. The aggregate demand is increased by stimulating consumption through a direct subsidization of households. When the quarterly growth rate is below the critical growth rate, all households receive a subsidy, where the individual subsidy is a percentage $s_{t}^{H H}$ of the household's consumption expenditures. As pointed out above, we assume that the subsidy rate $s_{t}^{H H}$ increases with the gap between the actual and the threshold growth rate. Thus, the larger the deviation of the growth rate from $g^{t h}$, the more subsidies are paid out to households. The size of the subsidy rate is determined according to the following equation:

$$
s_{t}^{H H}=\mu \cdot \tanh \left(\max \left[0, g^{t h}-g_{t-1}^{Q}\right]\right) .
$$

Besides the deviation of the quarterly growth rate from the threshold $g^{t h}$, the size of the subsidy rate depends on an exogenous parameter $\mu$. This parameter is used to control the intensity of the policy.

We assume that households know the conditions of the policy ex ante and take the subsidy as additional budget into account when deciding about consumption plans. However, it is not possible to retain and save the subsidies. Households have to spend subsidies immediately.

The second policy is a subsidization of firms' capital investments. When the policy is implemented, all investing firms receive a fraction $s_{t}^{I n v}$ of their investment expenditures as subsidies. Again, we assume that firms know the conditions of the policy ex ante and incorporate the subsidy in their investment decision by taking a reduced capital price into account. The subsidy percentage $s_{t}^{I n v}$ is determined according to the same rule as described in Expression 13 .

Also the third policy scenario considers an investment subsidization, but in contrast to the second policy, firms only receive subsidies if they choose the currently available best

\footnotetext{
${ }^{2}$ see, e.g., http://www.recovery.gov/Pages/default.aspx (accessed on February, 9th, 2015)

${ }^{3}$ The target growth rate is set such that it corresponds to the average growth rate of the technological frontier, which can be interpreted as the natural growth potential of the economy. The frontier grows at an annual rate of about $2 \%$. Thus, the threshold value at which the policy is activated is $g^{t h}=0.005$.
} 


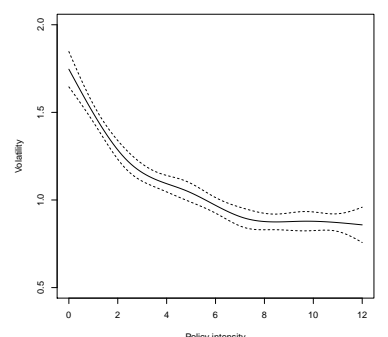

(a)

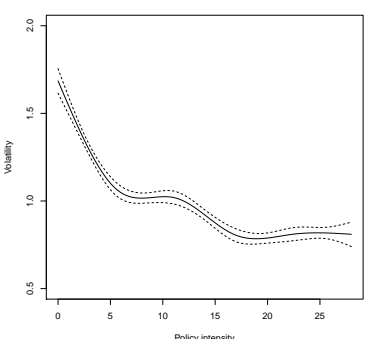

(b)

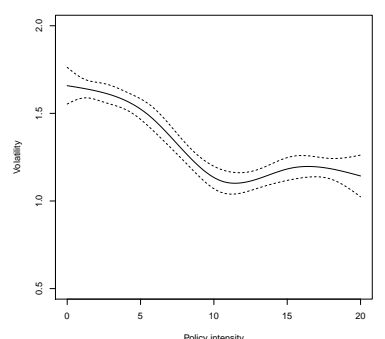

(c)

Figure 5: Spline smoothed effects of the consumption subsidy policy (a), investment subsidy policy (b), and technology subsidy policy (c) on the volatility of the business cycle.

practice technology for their investment. As for the other policies, the subsidy rate $s_{t}^{T e c h}$ is determined according to Equation 13

We set up simulations in which we vary the intensity parameter $\mu$ incrementally by steps of size 0.25 within an interval between null (i.e. no policy) and a maximum level $\mu_{\text {max }}$. This enables us to examine a quasi-continuation of policy effects and allows a better analysis and comparison of the three policies. Note that the maximum intensity is different for each policy. The values are chosen such that a further increase does not lead to a significant reduction of business cycle volatility. We have $\mu_{\max }=12.0$ for the consumption policy, $\mu_{\max }=28.0$ for the investment policy, and $\mu_{\max }=20.0$ for the technology policy. In order to obtain statistically robust results, we run 12 batch runs for each of the considered values of $\mu$.

\subsection{Policy Effects on the Business Cycle Volatility}

We now turn to the comparison of the three stabilization policies. The first policy question posed in Section 4.1 has been whether the policies are actually able to smooth the business cycle. A possible indicator for measuring business cycle volatility is the percentage standard deviation computed for the cyclical component of the time series total output from its HP filtered trend (see Section 3.9).

Figure 5 shows the estimated effects of a variation of the policy intensity $\mu$ on this volatility measure (see B for technical details). The three panels demonstrate that each of the considered policies can reduce the business cycle volatility. In that sense, the policies are suitable to achieve the primary goal for which they have been designed. The effects show qualitatively similar patterns. The estimated curves describing the relation between volatility and the intensity of the policies are convex. Thus, the policies are characterized by diminishing returns with respect to the intensity parameter $\mu$. Apparently, there seems to be a minimum level of volatility for each policy. The lower bounds are almost identical for the consumption and the investment subsidy policy while the minimum volatility of the technology policy is considerably higher.

It should be clear that a comparison of the policies based on Figure 5 cannot account for input efficiency. The reason is that the intensity parameter $\mu$ is used in different contexts such that equal values of $\mu$ are associated with different levels of additional government spending. To make the policies comparable in this respect, one has to replace $\mu$ by, e.g., an indicator measuring the average policy expenditures. In Figure 6 we show the re-estimated policy effects where we use the average monthly spending relative to the nominal GDP as input measures of the policies. Now one can see a clear difference between the three policies. For obtaining the same volatility reduction, the government must spend a considerable larger share of the GDP for the demand stimulating policy compared to the investment stimulating policy. And the technology subsidy, which cannot reach the same volatility reduction, requires the lowest expenditures. A further observation is that the presumption of diminishing returns still holds. Altogether, these observations lead to the first qualitative insight: 


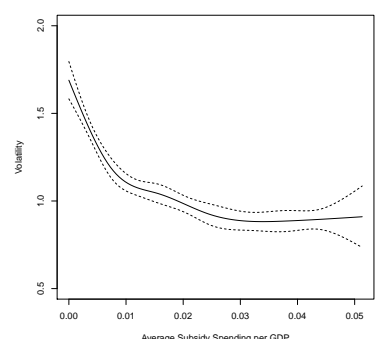

(a)

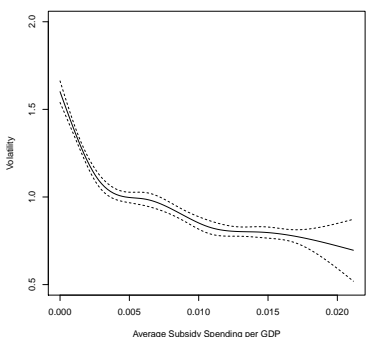

(b)

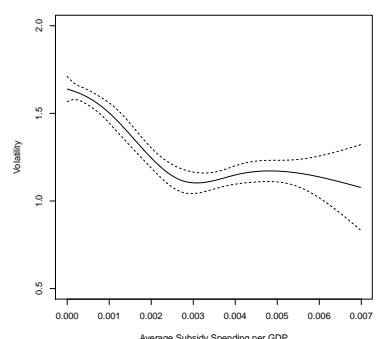

(c)

Figure 6: Estimated relation between business cycle volatility and policy expenditures per GDP (averaged over all periods) for the consumption subsidy policy (a), investment subsidy policy (b), and technology subsidy policy (c).

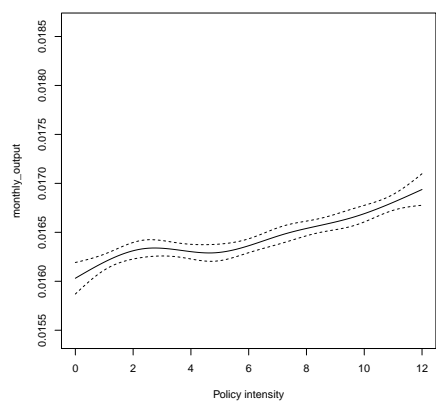

(a)

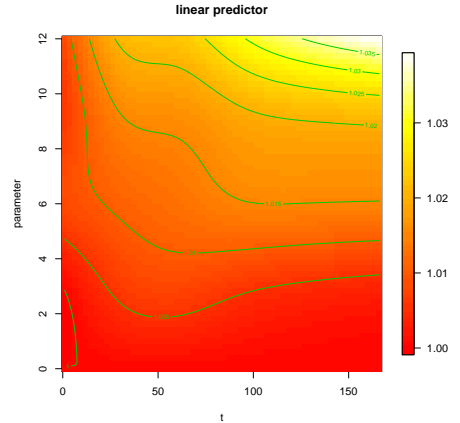

(b)

Figure 7: Left: Spline smoothed policy effect of a variation of the policy intensity $\mu$ on the average annual growth rate over the 500 simulation months; right: the policy effect on the time series of aggregated output. The color code indicates the time evolution of changes in total output relative to the baseline case without policy.

Result 1: All three policies lead to a substantial reduction of the business cycle volatility. However, the policies differ considerably in terms of their efficiency regarding the usage of fiscal resources. To obtain a similar volatility reduction, the government has to spend most funds for the consumption stimulating policy, while it has to spend considerably less for the investment and the least funds for the technology subsidizing policy.

\subsection{Policy Effects on Long-term Growth}

\subsubsection{The Consumption Stimulating Policy}

We now turn to the long-term growth effect of the three policies starting with the consumption subsidization. Figure 7 (a) shows for the considered range of the policy intensity $\mu$ the annual real growth rate of the economy, averaged over the 500 months of the simulations. The policy effect on economic growth tends to be positive and its strength increases with $\mu$. Without policy, the average annual growth rate is about $1.6 \%$ and rises up to approximately $1.68 \%$ for the highest considered intensity $\mu=12.0$.

In order to determine whether the growth effect is transient or permanent, - the former means a shift of the output trajectory and the latter a shift of the growth trajectory - we depict in panel (b) of Figure 7 the estimated relative effect on the time series of aggregated output. The heat map displays the time dimension in quarters at the horizontal axis and the different levels of policy intensity $\mu$ at the vertical axis. The color code indicates the relative deviation of total output from the baseline case without policy (see B for technical details). Apparently, the growth of the output premium is not constant over time. This observation, however, contradicts the hypothesis of a possible uniform shift of the growth trajectory. 

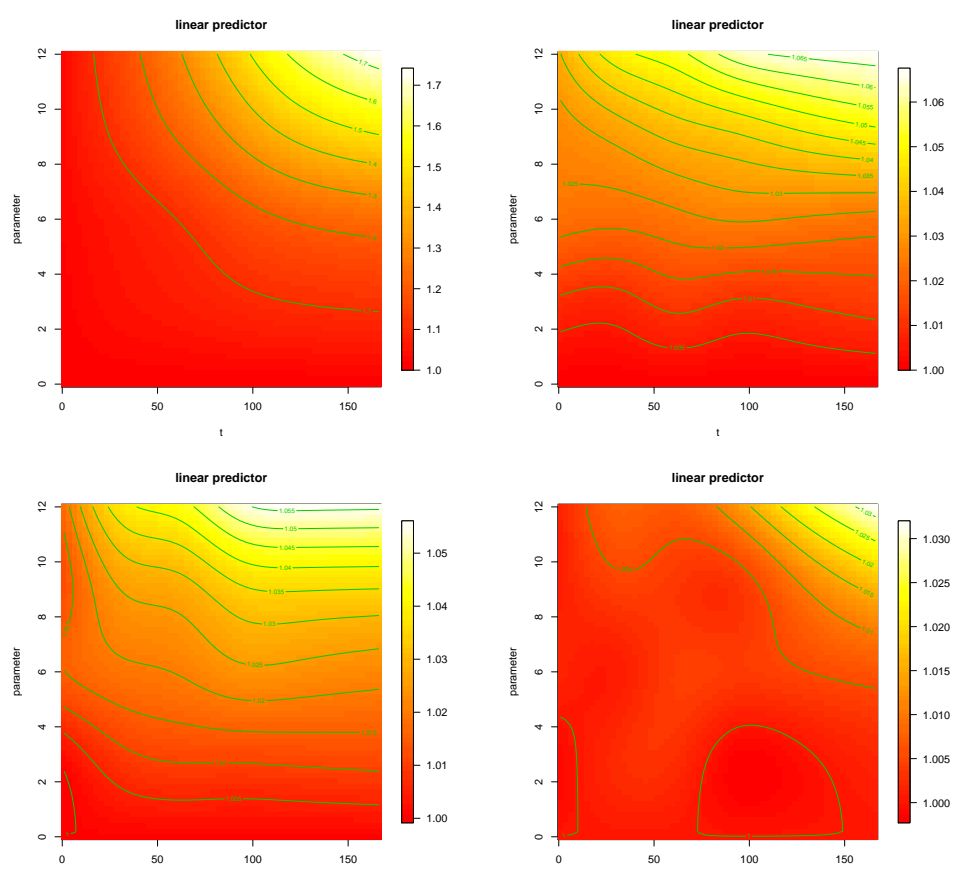

(c)

(d)

Figure 8: Policy effect on the nominal consumption budget (a), the deflated consumption budget (b), planned output quantities (c) and average productivity of the capital stock (d).

The policy is a classical demand-oriented policy measure that aims at supporting the economy through a stimulation of private consumption. A higher consumption level is supposed to increase firms' production, which prevents the economy from sliding into recession. The reduction of the business cycle volatility described above suggests that this mechanism actually works. But the policy leads not only to temporary effects on the consumption budget but also to a permanent effect. This can be seen in panel (a) of Figure 8 showing the overall effect of the policy on the households' consumption budget, which is clearly positive and steadily increasing over time. Adjusting for inflation uncovers the policy effect on the real consumption budget (panel b). Again, the effect is positive throughout the simulation but its size is smaller compared to the nominal effect. This suggests that the policy leads to increasing inflation.

In addition to the direct effect of the subsidies, the sustained effect on the nominal budget can mainly be explained by wage dynamics arising at a tightening labor market. Panel (c) of Figure 8 shows a positive policy effect on the planned output quantities. Compared to the actual output, it becomes apparent that firms cannot fully realize the desired production plans. There is a production gap that is mostly due to rationing at the labor market. The increasing demand at the consumption goods market leads to adjusted output targets, which in turn requires an adjustment of firms' work force. As a result, the employment level as well as the labor market tension increases such that it becomes more difficult to fill open vacancies. Hence, in order to attract workers, firms start increasing the wage competition, which implies rising base wage offers. Eventually, this leads to a higher nominal wage level, thereby contributing to the growing consumption budget. At the same time, as the wage increase is disconnected from the development of the productivity in the economy, the unit costs of firms increase as well. Since these additional costs are incorporated in the pricing of firms, the rising costs lead to inflation and deflate the growth of the nominal consumption budget.

Panel (d) presents the policy effect on the average productivity of capital in the economy. There is a positive effect on the productivity of firms for high policy intensities in the long run. The increasing productivity coincides the growing long-term output premium for high policy intensities (compare Figure $7 \mathrm{~b}$ ). This suggests that the positive long-term growth 


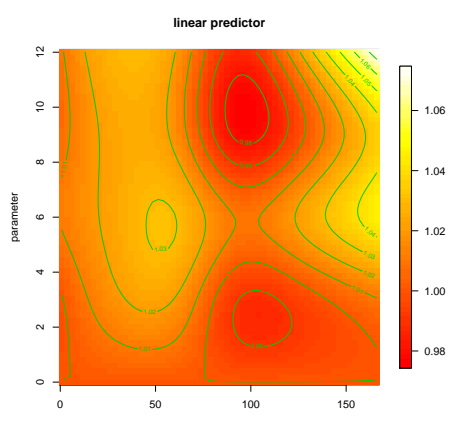

(a)

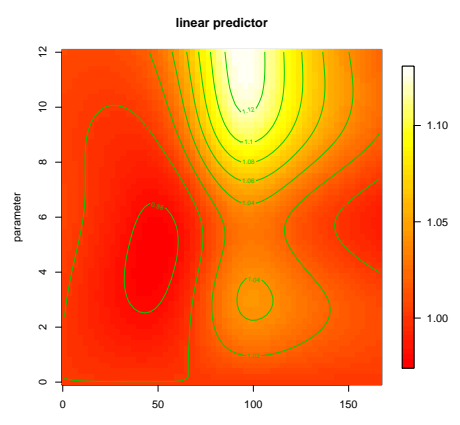

(b)

Figure 9: Policy effect on output levels of high-tech (a) and low-tech firms (b).

effect observed for high policy intensities is mostly technology-driven.

The emergence of this productivity fostering effect can be traced back to the fact that firms are heterogeneous with respect to productivity and output, and these heterogeneous firms are differently affected by the policy. To illustrate this connection, we depict in Figure 9 the evolution of the average output effect for high- and low-tech firms ${ }^{4}$ In fact, highand low-tech firms respond differently to the policy, where three distinct phases can be identified. In the short term, high-tech firms expand their production while at the same time the output of low-tech firms slightly declines. This leads to an overall increase of the output heterogeneity as high-tech firms produce on average more output than low-tech firms. As time elapses, the positive effect on the output of high-tech firms ceases and becomes negative, while at the same time low-tech firms increase their output. This is associated with a reduction of the output heterogeneity of firms in the medium term. And finally, the positive output effect on high-tech firms re-emerges in the long run. At the same time, the effect on low-tech firms declines.

How can the different behavior of low- and high-tech firms be explained? To understand the underlying mechanism, we first focus on what happens in the short term. The reason why high-tech firms benefit almost exclusively from the policy in the short run is that these firms start with a competitive advantage. At the outset, high-tech firms have (by definition) a higher technological productivity as well as a superior human capital endowment. Both translates into cost advantages that allow high-tech firms to set lower prices without substantially impairing the price costs margin. This competitive advantage in turn gives high-tech firms scope to respond more aggressively on the additional demand generated by the policy. When the policy is introduced, high-tech firms make use of their higher competitiveness and grab most of the additionally emerging demand.

The initial output expansion of high-tech firms comes along with a relative increase of labor demand, which intensifies the competition on the labor market and drives the dynamics of wage offers. This competitive pressure is mostly fueled by two generic phenomena of the base scenario without policy; first, high- and low-tech firms differ in their relative attractiveness for workers with different general skills, where high-tech firms offer competitive wages only for high-skilled workers. And second, the unemployment rate of high-skilled workers is substantially lower and high-skilled workers are almost exclusively employed by high-tech firms. As a consequence, high-tech firms must aim at attracting low-skill workers for open job positions. Since the wage offers for low-skilled workers are not competitive in this period, high-tech firms have to adjust their wage offers by increasing the base wage offer.

Rising base wage offers are associated with increasing wages that firms have to pay to their employees. These wage increases are cost-relevant as they are disconnected from the productivity growth and result in higher unit (labor) costs. As described above, base wage offers between high- and low-tech firms are shifted towards high-tech firms with the consequence that high-tech firms lose some of their cost advantages. At the same time, high-tech

\footnotetext{
${ }^{4}$ High-tech firms in period $t$ are those firms whose productivity is above the median productivity in $t$. Accordingly, low-tech firms are those firms with productivity below the median.
} 


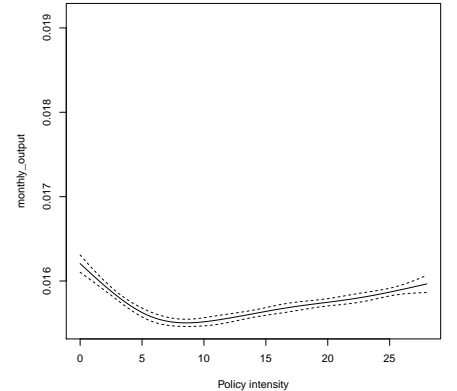

(a)

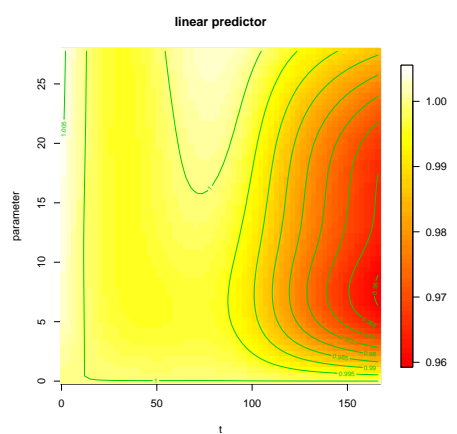

(b)

Figure 10: Spline-smoothed policy effects of the investment subsidizing policy on quarterly growth rates of output (a) and on the evolution of aggregated output.

firms have to set prices more aggressively in order to expand and sell the additionally produced output. Consequently, high-tech firms forfeit some of their relative profitability and competitiveness over this period. Altogether, the observed phenomena reduce the competitive pressure on low-tech firms and enable them, at a certain point in time, to choose a more aggressive competitive strategy. This gives rise to a relative reduction of their prices and a relative expansion of output quantities. As a consequence, we observe the transition to the medium-term state of the economy, in which low-tech firms expand relative to the base scenario, whereas high-tech firms lower their output.

The shift of the relative output towards low-tech firms in the medium run is associated with an increasing labor demand of low-tech firms. In order to adjust the workforce, low-tech firms start intensifying the wage competition such that the shift of the relative base wage offer towards high-tech firms ceases. Eventually, this relative increase of labor demand initiates an inverse repetition of the mechanism described above, which now leads to a relative loss of competitiveness of low-tech firms. This results in the emerging output divergence between low- and high-tech firms in the long run. This divergence explains the increase of the economy-wide productivity and finally the increasing aggregate output. Putting all implications together, we can summarize the effectiveness of the consumption subsidizing policy in the following qualitative insight:

Result 2: The consumption subsidizing policy has an amplifying effect on the longterm growth in the economy and leads to more employment. At the same time, the policy induces more inflation. The positive long-term growth effect for high policy intensities is technology-driven by a faster diffusion of new technologies. This accelerated diffusion is the result of different policy reactions of heterogeneous firms in the short run that, due to path dependencies, lead to a relative expansion of high-tech firms in the long run.

\subsubsection{The Investment Subsidy Policy}

Quite a different picture emerges compared to our discussion in the previous subsection, if we consider the implications of the investment subsidizing policy. Under this policy, a firm receives a public subsidy when it invests in physical capital. The size of this subsidy depends on the intensity of the policy $\mu$ and the deviation of the quarterly growth rate from the threshold value $g^{\text {th }}$. Firms take this subsidy into account when deciding about investments.

Figure 6 on page 19 has indicated that the investment subsidizing policy can achieve the same reduction of the business cycle volatility as the consumption policy. A comparison of the growth effects, however, reveals a substantial difference between the two policies. While the consumption subsidization has a positive growth effect, the investment policy has a negative effect on the long-term growth rate (Figure 10 a). Furthermore, the growth effect is not monotonic in $\mu$; rather, the effect appears to be U-shaped with its strongest negative impact for moderate levels of $\mu$ (between 5 and 15). In panel (b) we display the emerging dynamics of the policy effect on the aggregate output trajectory. Apparently, the policy 


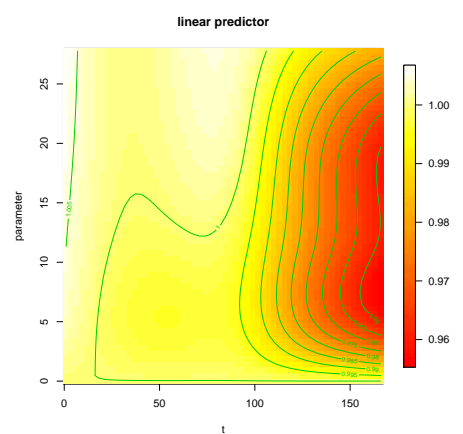

(a)

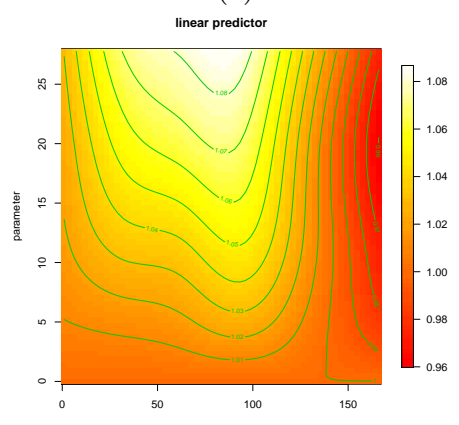

(c)

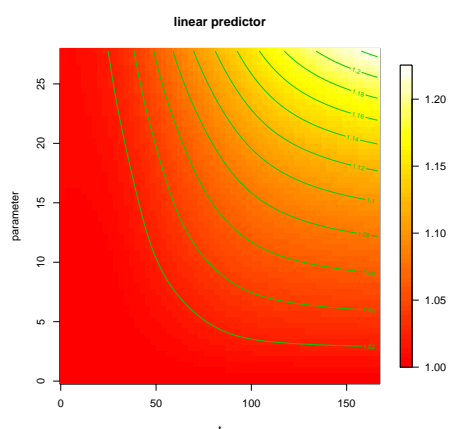

(b)

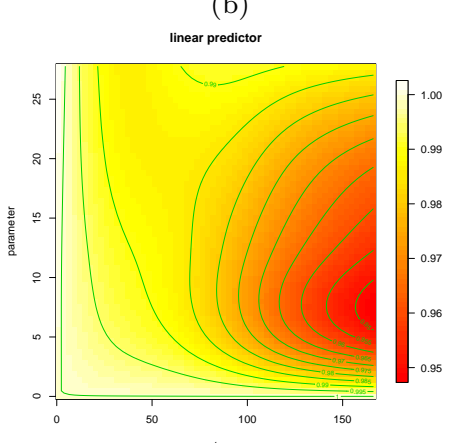

(d)

Figure 11: Policy effect on the aggregated level of planned output (a), nominal consumption budget (b), posted vacancies (c) and average capital productivity (d).

generates not only a non-monotonic impact on the average growth rate but also highly non-linear effects on the output trajectory. While there is virtually no effect in the first two-thirds of the encompassed time, one can observe the emergence of a negative output effect in the last third of the simulation. It is in any case worth noting that the emergence of a negative policy effect depends not only on the intensity of the policy itself but also on the considered time horizon.

The lack of additional aggregate output in the short term is thereby consistent with the absence of any positive effect on the trajectory of the aggregated planned output (see Figure 11 a). This is true even if the policy has a positive impact on the growth of the consumption budget (panel b). The increase of the consumption budget is thereby driven by labor market dynamics. Although there is no effect on planned and actual output in the short term, one can observe a positive effect on the number of posted vacancies (panel c) and the number of vacancies remaining unfilled. The higher labor demand leads to an increase of wage offers and eventually of nominal wages. Since labor is the most important source of income, rising nominal wages translate into rising consumption budgets. On the other hand, the wage increase leads to higher unit costs of firms that are incorporated in the prices. As a result, the additional growth of the consumption budget is offset by more inflation.

But why does the policy lead to a negative output effect in long run? The negative output effect is mostly due to a strong convergence between high-and low-tech firms in the long run. While catching up, low-tech firms account for most of the investments, thereby systematically investing in less productive technologies. This results in a declining overall productivity in the economy as illustrated in Figure 11 (d).

The output convergence between high- and low-tech firms in the long run is highlighted in Figure 12, which depicts the policy effects on output separately for high- and low-tech firms. Moreover, figure 12 reveals another observation: while there are no dynamics on the aggregate output level before the long run, one can observe highly dynamical pattern at the disaggregated level. Similar to the case of consumption subsidies, low- and hightech firms behave differently in response to the policy. But, in contrast to the consumption policy, high-tech firms react in the short run by contracting and low-tech firms by expanding. Apparently, as a major difference to the consumption subsidizing, low-tech firms rather than 


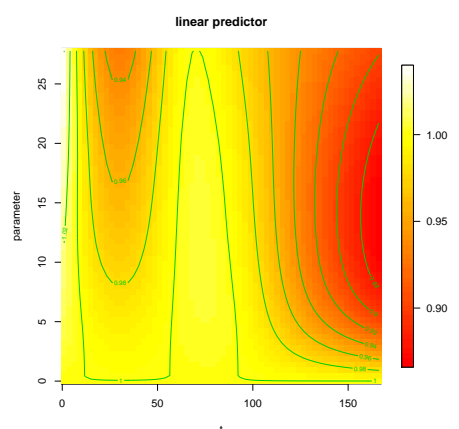

(a)

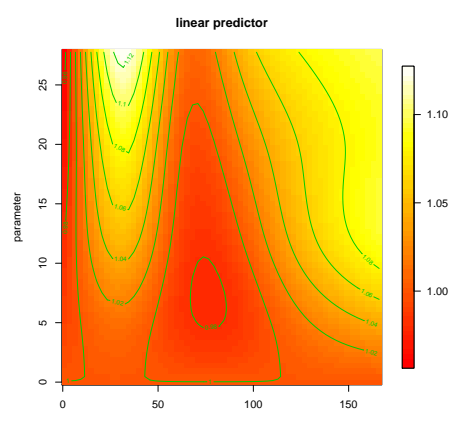

(b)

Figure 12: Policy effect on output levels of high-tech (a) and low-tech firms (b).

high-tech firms benefit more from the investment subsidies after the first implementation of the policy. In the aggregate, the increase of output of low-tech firms offsets the declining output of high-tech firms such that no significant effect on total output emerges.

Why does the policy give low-tech firms more incentives to expand in the short term? As already pointed out in Section 4.3.1. high- and low-tech firms differ with respect to wage offers; while high-tech firms offer competitive wages for high-skilled workers, low-tech firms post competitive wage offers for low-skilled workers. At the same time, the employment level of high-skilled workers is considerably higher. As a consequence, a great share of the stock of available workers consists of low-skilled workers. This implies a structural disadvantage of high-tech firms in hiring additional workers during this period.

The policy does not generate more real demand in the short term. Hence, a short-term expansion of high-tech firms could only be reached by implementing an aggressive pricing strategy that forces low-tech firms out of the market. But as they also face labor market rigidities which make aggressive pricing more expensive, high-tech firms assess this strategy as being non-profitable. In this case, the subsidies are taken as windfall gains without triggering further investments. At the same time, the initial investment level of low-tech firms is low, i.e. most of the low-tech firms appraise capital investments as not being worthwhile given the current market environment. With subsidized capital prices, investments become cheaper and the likelihood of an investment project to break even increases. This results in more investments of low-tech firms and consequently affects their production capacity. Together with the higher attractiveness for better available low-skill workers, an increased production capacity gives low-tech firms the opportunity to gain additional market shares.

The expansionary strategy of low-tech firms in the short run is associated with intensified labor market activities that trigger the cost-driving increase of base wage offers. Eventually, the higher production costs in combination with the aggressive pricing lead to a decline of low-tech firms' profitability that limits the scope of action for keeping the aggressive competitive strategy. In the following, low-tech firms relax the expansion, which gives hightech firms the opportunity to adjust the strategy toward a more competitive one. The changing competitiveness explains why there the process of convergence between high- and low-tech firms ceases temporarily in the medium term.

Figure 11 (c) has illustrated that the labor market is characterized by a high tightness in the medium run. This is exactly when high-tech firms pursue an expansionary strategy. The high labor market tension has basically two effects on the expanding high-tech firms: first, it increases the costs of hiring workers such that eventually the production costs of high-tech firms rise. And second, a greater share of the cohort of new employees hired by high-tech firms belongs to the group of low-skilled workers. An enhanced recruitment of low-skilled workers leads to declining specific skills and general skills. The negative effect on high-tech firms's specific skills emerges as the additionally hired low-skill workers have a lower specific skill level compared to the incumbent workers. This is due to the fact that these workers have mostly been employed by low-tech firms. The reduction of the general skill level has a negative effect on the vintage choice. This in turn reduces the productivity of the capital stock and amplifies the negative effect on the specific skills. Altogether, this 


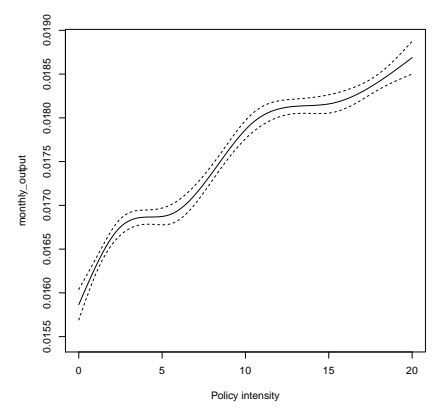

Figure 13: Spline-smoothed policy effects of the technology subsidizing on the average annual growth rate (b).

leads to a loss of competitiveness forcing high-tech firms to relax the expansionary strategy after a certain period.

In the long run, low-tech firms take advantage of their improved relative costs structure and re-start expanding. This output expansion is thereby fueled, on the one hand, by the investment subsidies, which make the required adjustment of the capital stock cheaper, and, on the other hand, by the fact that the labor market tension in the long run declines, which prevents the emergence of similar cost dynamics as described above. This results in the output convergence between high- and low-tech firms. As low-tech firms invest in less productive vintages, the reallocation of workers from high- to low-tech firms leads to an inefficient employment of the resources of the economy. As a consequence, the output gain for low-tech firms cannot compensate the output loss of high-tech firms such that the overall output effect is negative. Altogether, the findings regarding the investment policy can be summarized in the following qualitative result:

Result 3: Despite a positive effect on the investment activities in the short and medium term, the investment subsidizing policy does not generate additional output growth. Instead, it has no growth effect in the short and medium term but a negative growth effect in the long run. At the same time, the policy has an employment-promoting effect. But the higher employment does not lead to more output since the policy causes also a negative effect on the technological productivity of the capital stock in the economy. The negative long-term effect on productivity is due to a relative expansion of low -tech firms in the long run, which is the result of path-dependencies triggered by differing policy reactions of high-and low-tech firms in the short run.

\subsubsection{The Technology Subsidy Policy}

The technology subsidizing policy is the third stabilization policy that has been identified in Section 4.2 as being successful in smoothing the business cycle. The general principle of this policy is similar to the principles underlying the investment policy with a crucial difference: only those investments are subsidized that will flow into the most up-to-date technology.

Figure 13 shows the policy effect on the long-term growth. The technology policy has a positive effect on the long-term growth of the economy, where the average annual growth rate increases from $1.6 \%$ up to $1.9 \%$, which is clearly the strongest growth effect of the three considered policies.

Figure 14 illustrates how the policy affects the evolution of the aggregated output. Panel (a), which depicts the effect on the output level, shows that the additional average growth is translated into a growing output premium. Panel (b) displaying the policy effect on the quarterly growth rates highlights that the growth effect does not unfold immediately.

The idea behind the technology policy is to provide incentives for firms to invest in the best practice technology. This is supposed to increase the speed of technological diffusion, which, through a consequently higher productivity in the economy, might generate additional and sustainable real growth. Panel (c) shows how the policy affects the average vintage 


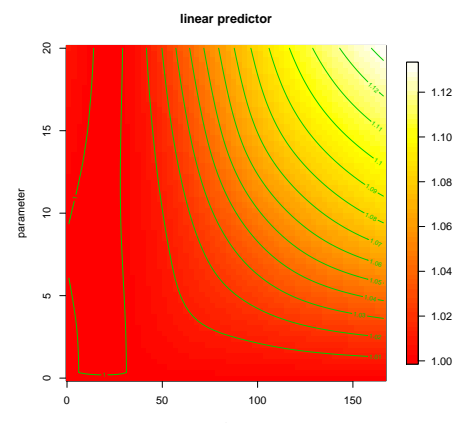

(a)

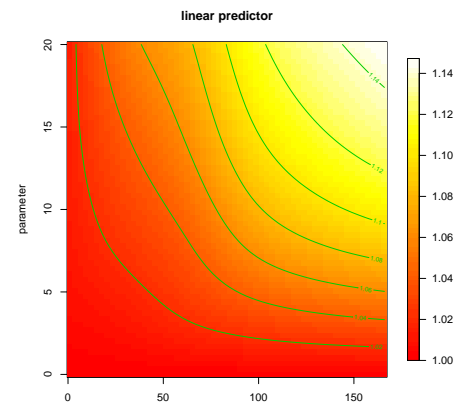

(c)

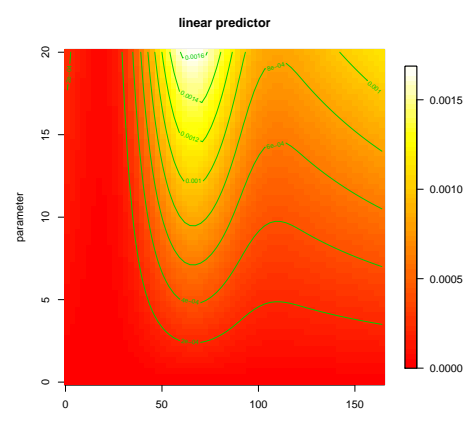

(b)

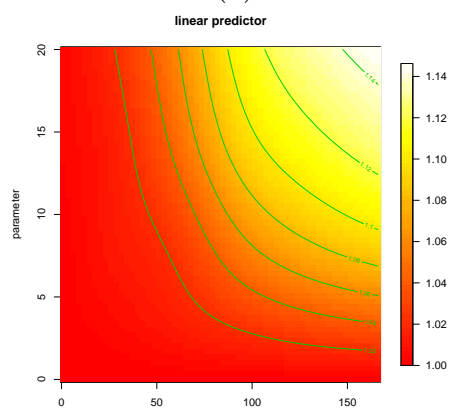

(d)

Figure 14: Spline-smoothed policy effects of the technology subsidizing on the evolution of aggregated output (a), the evolution of quarterly growth rates (b), productivity of the average vintage choice (c), and the average capital productivity (d).

choice of firms. Generally, the average productivity of the acquired capital is significantly higher compared to the base scenario suggesting that, indeed, the policy affects the average vintage choice of firms positively. Moreover, the effect seems to become stronger over time but also stronger for higher policy intensities. Panel (d) shows the impact of the policy on the average productivity of the capital stock. One can see that the positive effect on the vintage choice translates into a substantial increase of the productivity. Quantitatively, the strength of the effect on capital productivity resembles the effect on the output trajectory. It appears that most of the growth of total output is driven by the faster diffusion of new technologies.

According to the wage adjustment rule described in Section 3.6, the productivity growth triggered by the policy is passed on the wages of workers and causes additional growth of nominal wages. In this case, however, the resulting higher labor expenditures are compensated by a higher productivity such that firms' unit labor costs are not forced up. This has two implications: First, with the nominal wages also the nominal consumption budget increases. And second, the low cost effects of the policy avoid a similar inflation pressure as it has been observed for the consumption and investment policy. Hence, only a small share of the additionally generated nominal demand is inflated. As a result, the policy generates not only nominal demand but also a considerable amount of real demand. This real demand can be satisfied as the economy becomes more productive.

As in the discussion of the two other policies, we now turn to a more differentiated discussion of the policy implications for the heterogeneous firms. In Figure 15 we depict the policy effect on the output trajectory of high-tech and low-tech firms. In the short term, the technology policy generates a negative effect on the output trajectory of high-tech firms, whereas low-tech firms can increase their output. Both translates into a short-term reduction of output heterogeneity. In the medium term, however, high-tech firms intensify the output growth such that the gap to the output level of the base scenario starts to decline. At the same time, the low-tech firms lower their output with the result that the output heterogeneity increases. This process continues into the long run.

But how does the policy affect the vintage choice of high- and low-tech firms? Figure 16 


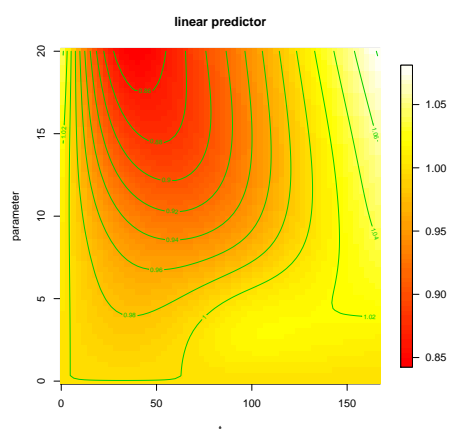

(a)

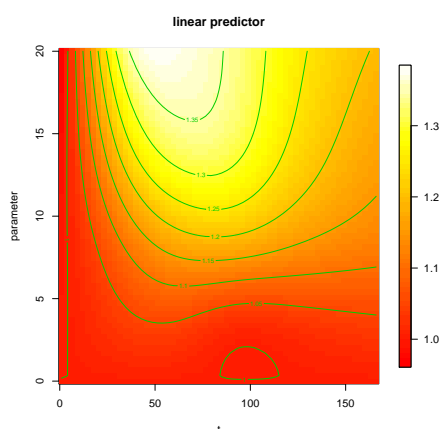

(b)

Figure 15: Policy effect on the aggregated output trajectory of high-tech (a) and low-tech firms (b).

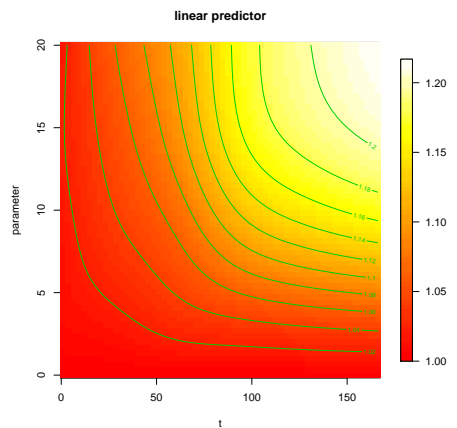

(a)

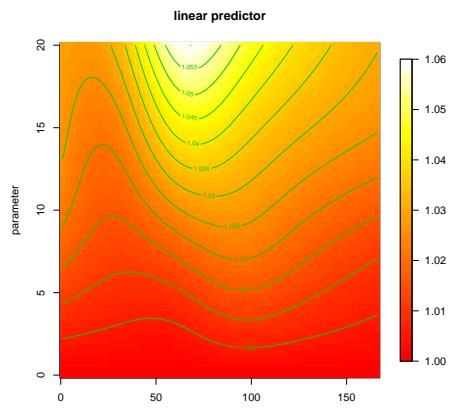

(b)

Figure 16: Policy effect on the vintage choice of high (a) and low-tech firms (b).

illustrates that there are substantial differences between the policy effects on high- and lowtech firms. More precisely, the vintage choice of low-tech firms is less affected compared to the vintage choice of high-tech firms, where the difference builds up over time. Even with subsidies, there is still a considerable gap between the productivity of purchased capital of low-tech firms and the frontier productivity.

The mechanism that leads to the initially differing competitive responses of high- and lowtech firms is basically the same as for the investment policy. Since the technology subsidizing does not affect the market demand in the short run, high-tech firms react passively. This is because an increased production capacity would only lead to higher market shares when high-tech firms implement a predatory pricing strategy. At the same time, high-tech firms also face the structural disadvantage at the labor market that the more available low-skilled workers prefer to work for low-tech firms. As a consequence, high-tech firms would have to increase the base wage offers in order to attract more workers. This would increase the unit costs and would reduce the profit prospects for an aggressive competitive strategy. For low-tech firms, in contrast, the policy reduces investment barriers such that they have the opportunity to build up production capacities. At the same time, they have better access to the available pool of workers and can hire the amount of employees required for an expansionary strategy.

But how does the targeting of the investment subsidies contribute to the differences to the case of untargeted subsidies in the investment policy scenario? An explanation is that, in contrast to the investment policy, the technology policy has quantitatively different effects on the productivity of high-tech and low-tech firms in the short term. At the outset of the simulation, the general skill distribution is highly polarized among high- and lowtech firms. Since high-tech firms have a high average general skill level, the vintage choice of these firms is already close to the frontier. In this case, the subsidizing has almost no impact on their productivity. On the contrary, due to the low average general skills, the vintage choice of low-tech firms is off the frontier. This productivity gap provides more scope 
for the policy to affect the productivity of low-tech firms. Actually, low-tech firms intensify their investments, thereby choosing the best practice technology more frequently during this period. As a consequence, the productivity of the capital stock of low-tech firms shows a much higher growth rate than the productivity of high-tech firms. This technological catchup improves low-tech firms' position in the competition and amplifies the output convergence in the short run.

Nevertheless, in order to achieve the required expansion of the workforce, low-tech firms have to increase the base wage offers, which eventually drives the production costs. This in turn gives high-tech firms the opportunity to gradually increase the output in the medium run. The emerging output expansion of high-tech firms is accompanied by intensified investments where these investments strongly improve the capital productivity through the targeting of the investment subsidies. As a result, the process of productivity convergence stops and turns into divergence. The diverging productivity widens the spread between the wage offers for high-skill workers so that high-tech firms can increase the attractiveness for this skill group. In the following, a self-reinforcing feedback effect emerges that causes the divergence of firms' capital productivity and output in the long term: Due to the improved relative attractiveness, high-tech firms can increase the share of high-skilled workers in their workforce, while the average general skill level of low-tech firms declines. As the subsidizing of the best practice technology is not as effective for low-tech firms as for their high-tech competitors, the declining general skill level reduces the average productivity of their vintage choice. As a consequence, the productivity level of low- and high-tech firms diverge further, which amplifies the advantage of high-tech firms at the labor market to hire high-skill workers. This in turn reinforces the polarization of the general skill distribution among firms. In the end, low-tech firms have no possibility for catching up technologically as their general skill level is now clearly inferior. Moreover, they cannot increase the workforce as soon as the low-skilled labor force is exhausted. For this reason, one can observe the long-term divergence of low- and high-tech firms in terms of output and productivity. Wrapping up the observations, we can write the following qualitative result:

Result 4: The business cycle smoothing by subsidizing the adoption of the best practice technology leads to strong and sustainable long-term growth. This growth effect arises through a faster diffusion of new technologies and the resulting more productive capital stock in the economy. At the same time, the policy has almost no effect on inflation. The long-term growth effect is amplified by a crowding out of low-tech firms, which is triggered by high-tech firms mostly benefiting from the technology policy.

\subsection{Robustness Checks}

The policy results discussed in the previous section have been obtained from simulations conditioned on the specific setting of exogenous model parameters. However, a variation of single model parameters or interaction effects of a simultaneous variation of multiple parameters can have substantial impacts on the simulation outcome, which might influence the results of the policy analysis. For this reason, it is important to analyze whether the policy analysis is robust against a variation of model parameters.

In this subsection we describe robustness checks that study the effects of a variation of the model's parametrization on the outcomes of the policy scenarios. In particular, we focus on the robustness of the qualitative results of the policy experiments with respect to the reduction of the business cycle volatility and the impacts on the long-term growth rate. For each stabilization policy, we have run simulations in which the parameter setting has been determined by independent and uniformly distributed random draws from a parameter space that covers $30 \%$ intervals around the default parameters values of the model parameters (see Table 1). Additionally, we have drawn values for the policy intensity parameter $\mu$ randomly from the ranges between 0 and the maximum intensities $\mu_{\max }$. Altogether, we have run 1500 Monte Carlo simulations based on these random parameter settings for each of the policies. The pooled simulations can then be used to estimate regression models with longterm growth and short-term volatility as dependent variables, in which model parameters and the policy intensity $\mu$ are deployed as covariates. 


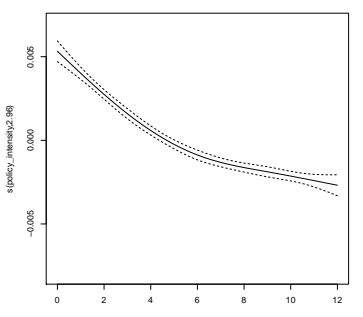

(a)

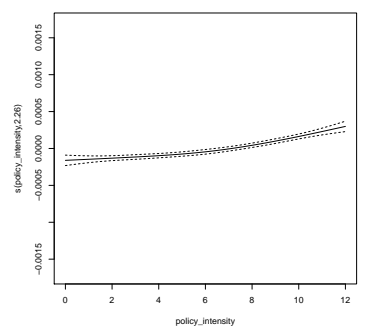

(d)

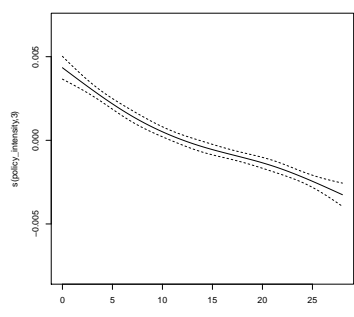

(b)

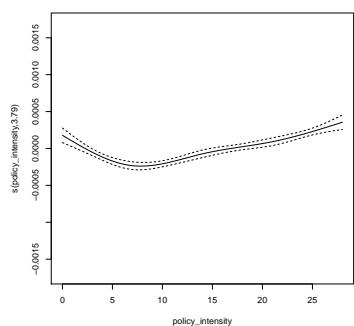

(e)

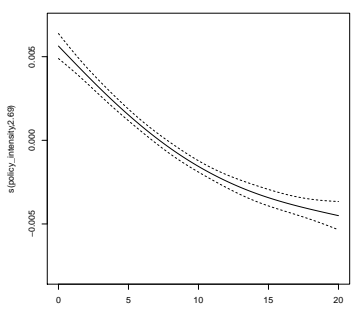

(c)

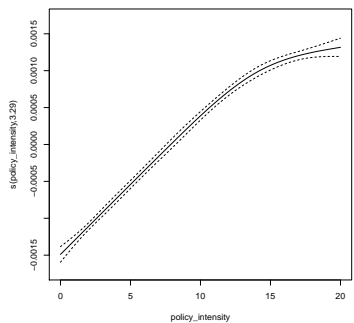

(f)

Figure 17: Estimated smooth terms for the policy intensity $\mu$. The smooth terms are estimated for the business cycle volatility (upper row) and growth rate (lower row) for the consumption policy (left column), investment policy (middle column) and technology policy (right column).

There are basically two types of effects of particular interest; the one is the isolated effect of the policy intensity on growth and volatility, which can be used to generally check whether the random choice of model parameters changes the effects of the policies substantially. To extract the isolated effect, we formulate a Generalized Additive Model (GAM) in which all model parameters and the policy intensity are wrapped in independent smooth functions. We obtain the following estimated model:

$$
g=g_{0}+s_{\mu}(\mu)+\sum_{l=1}^{L} s_{l}\left(\xi_{l}\right) .
$$

$g$ is the dependent variable (i.e. growth rate or business cycle volatility), $g_{0}$ is a parametric intercept and $\xi_{l}$ with $l=1, \ldots, L$ is the set of model parameters. The estimated smooth function $s_{\mu}(\mu)$ indicates the isolated effect of the policy on the dependent variable $g$.

The second type of effects are joint effects of $\mu$ with each of the model parameters. These joint effects are supposed to illustrate how the policy impacts are affected by a variation of each particular model parameter. The joint effect of the policy intensity and a parameter $\xi_{k}$ can be obtained by estimating the following GAM:

$$
g=g_{0}+\sum_{l=1}^{k-1} s_{l}\left(\xi_{l}\right)+\sum_{l=k+1}^{L} s_{l}\left(\xi_{l}\right)+t e\left(\mu, \xi_{k}\right) .
$$

In this model, each parameter except $\xi_{k}$, for which the interaction is assessed, is included in independent smooth functions to capture their impacts on the dependent variable $g$. The tensor product smooth function $t e\left(\mu, \xi_{k}\right)$ indicates the joint effect and can be interpreted as the effect of the policy intensity $\mu$ conditioned the parametrization of $\xi_{k}$.

Let us first consider the isolated effects of the policies given the random choice of model parameters. Figure 17 depicts the estimated smooth term $s_{\mu}$ representing the isolated effects on the business cycle volatility (upper row) and average growth rate (lower row) for the three policies. The figure clearly indicates that the qualitative effects stay intact even if we deviate from the default parametrization and select the parameter values randomly from a wider parameter space around their defaults.

We now turn to the joint effects. In the following discussion we report the interaction effects only for selected model parameters. For the business cycle volatility we present the 


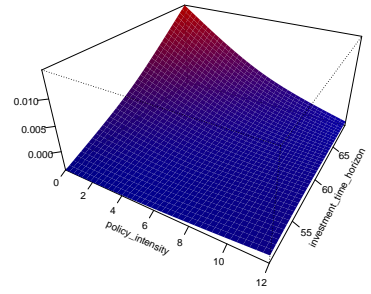

(a)

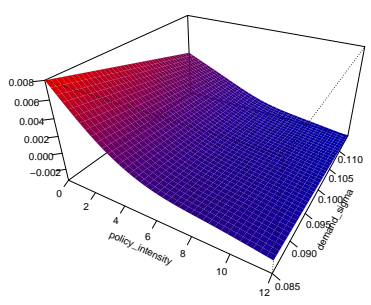

(d)

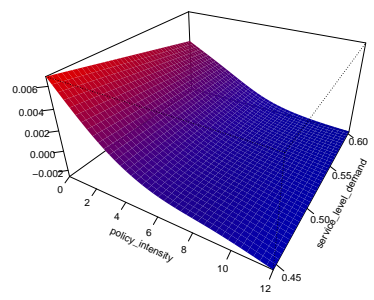

(g)

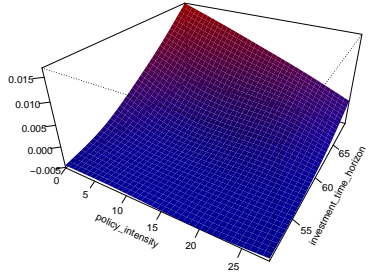

(b)

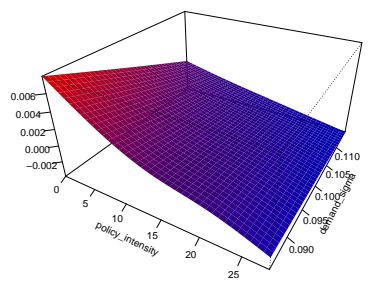

(e)

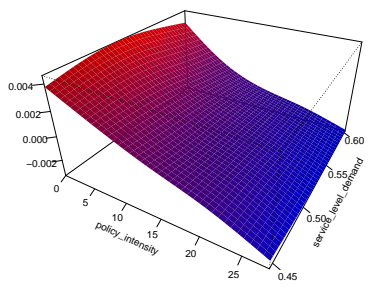

(h)

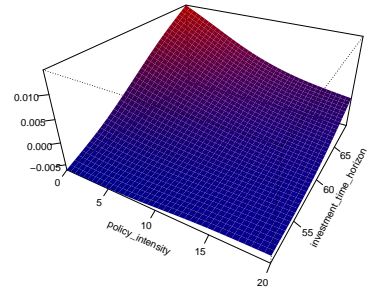

(c)

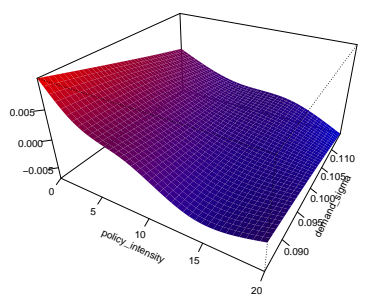

(f)

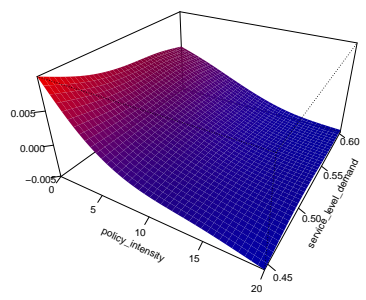

(i)

Figure 18: Joint smooth terms of the policy intensity and the parameter investment planning horizon $T^{L T}$ (upper row), expected demand volatility $\sigma_{D}^{2}$ (middle row), and service level of demand $\chi^{S}$ (lower row), estimated for the GAM explaining the business cycle volatility. Left column: consumption policy, middle column: investment policy, right column: technology policy.

interaction for the parameters investment planning horizon $T^{L T}$, expected demand volatility $\sigma_{D}^{2}$, and service level in the production planning $\chi^{S}$. For the average growth rate we limit the discussion on the depreciation rate $\delta$, the investment planning horizon $T^{L T}$, the speed of technological change $\Delta q^{i n v}$ and the intensity of consumers' choice $\gamma^{C}$. We opt for these parameters as they have been identified to have the strongest impacts on the business cycle volatility and the average growth rate (see Harting, 2014). We have also checked the interaction effects for the other parameters but, compared to the effects of the parameters above, they are qualitatively similar and quantitatively negligible.

Figure 18 and 19 show the estimated joint effects of the sensitive parameters and the policy intensity $\mu$ (i.e. the tensor product smooth term $t e\left(\mu, \xi_{k}\right)$ ) on the business cycle volatility (Figure 18) and long-term growth rate (Figure 19). Apparently, the variation of the sensitive model parameters does not qualitatively change the effect of the three policies. Altogether, a variation of model parameters in the neighborhood around their default values does not change the qualitative findings of the policy analysis. This means the results are robust and valid not only for the specific parameter setting used for the policy experiments.

It should be noted that this does not mean that the effects identified in the policy analysis are generic results which can be obtained from any parametrization of the model. However, the parametrization used for the experiments has not been chosen arbitrarily. It 


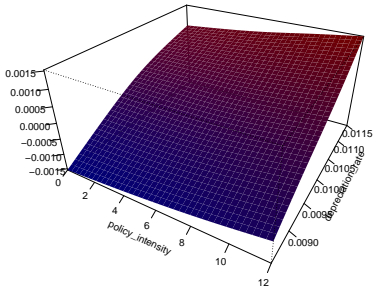

(a)

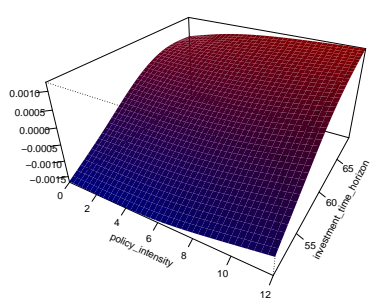

(d)

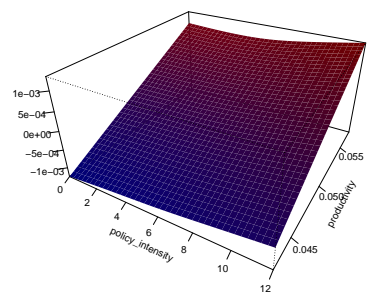

(g)

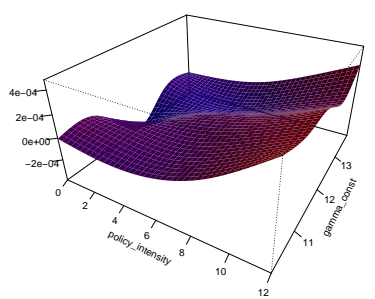

(j)

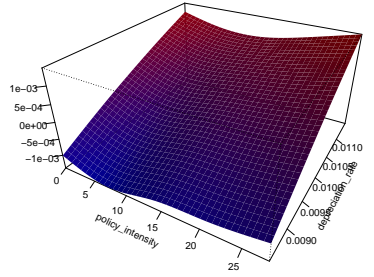

(b)

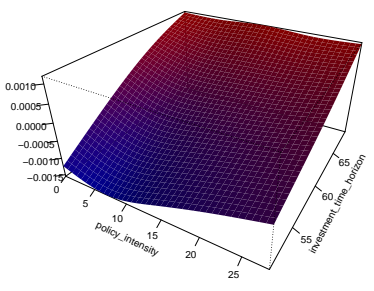

(e)

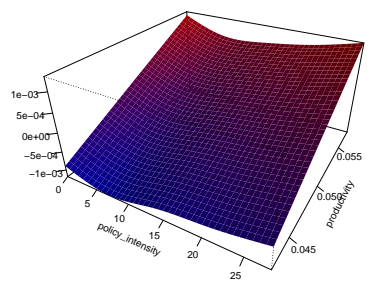

(h)

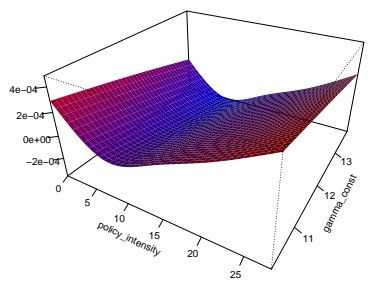

(k)

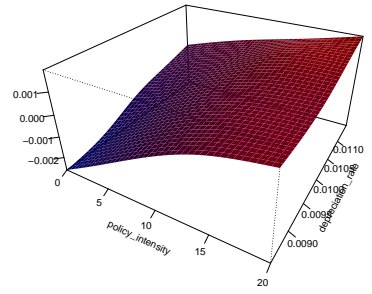

(c)

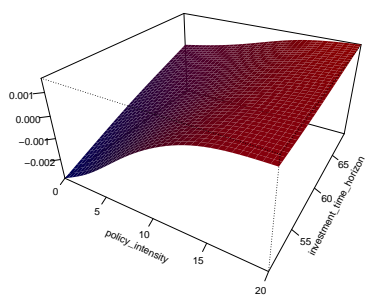

(f)

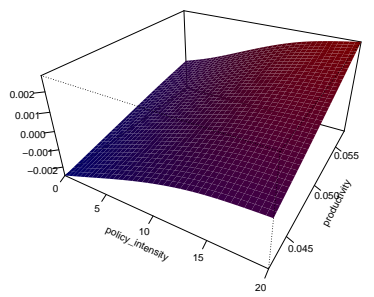

(i)

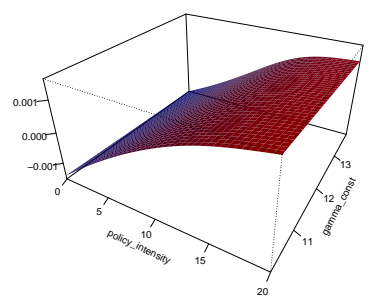

(l)

Figure 19: Joint smooth terms for the policy intensity and the parameter depreciation rate $\delta$ (first row), investment planning horizon $T^{L T}$ (second row), speed of the frontier growth $\Delta q^{i n v}$ (third row), and the intensity of consumers' choice $\gamma^{C}$ (fourth row), estimated for the GAM explaining the average growth rate. Left column: consumption policy, middle column: investment policy, right column: technology policy.

has rather been obtained from a systematic attempt to estimate and calibrate the model. The underlying assumption for this parametrization method is that the parameter space is restricted by, on the one hand, empirically observed values for parameters that have empirical counterparts and, on the other hand, by values for the other parameters that lead to economically reasonable simulation outcomes. The parametrization used for the simulations represents such a specification and a too strong deviation from this parameter setting is associated with a general reduction of the economic prediction power of the model. 


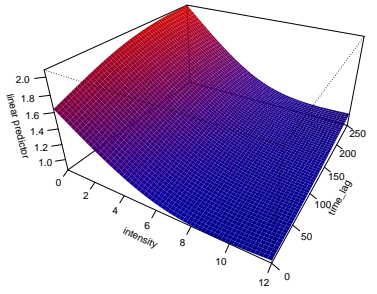

(a)

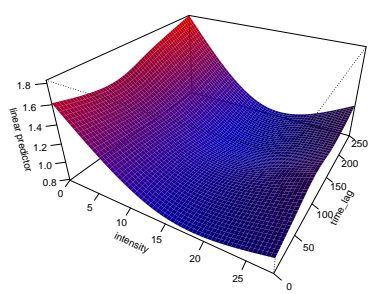

(c)

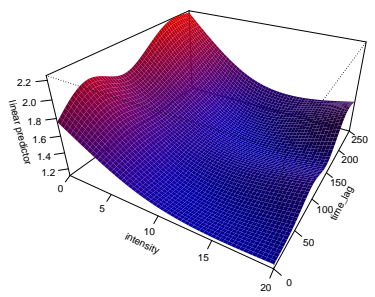

(e)

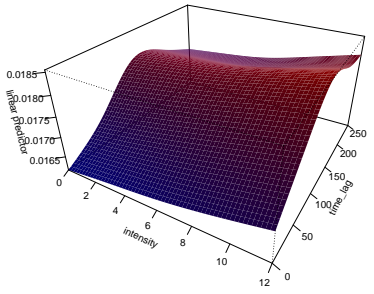

(b)

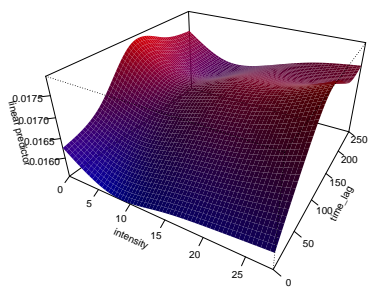

(d)

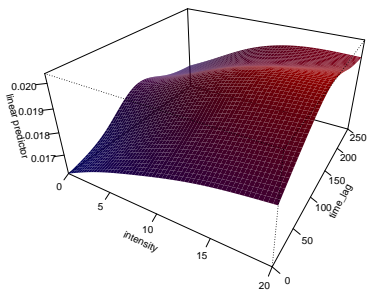

(f)

Figure 20: Policy effects of the consumption (upper row), investment (middle row), and technology subsidizing policy (lower row) on volatility (left column) and average growth rates (right column) for different initial conditions of the economy.

Besides the parametrization of the model, the initial condition of the economy can also have a strong impact on the simulation outcome. The initial condition describes the endowment and memory of agents with which they enter the first iteration of the simulation. In Section 3.8 we have explained that the start state used for the experiments has been a snapshot of a pre-simulation. The pre-simulation started with an equal initialization of all agents except for some variables as, for example, the general skill endowment of households. The iteration used as start state for the simulations has been chosen such that the simulation has passed the transient phase.

In the following, we want to demonstrate that the results from the policy analysis are also qualitatively robust against a variation of this specific start state. Therefore, we have run a set of simulations based on the default parametrization in which we varied the date $T^{P o l}$ at which the stabilization policies are introduced for the first time. Actually, this leads to an expansion of the pre-simulation, so that also here the start states are not determined arbitrarily. The maximum deferral of the policy implementation is by 250 months so that we vary $T^{P o l}$ between month 1 and month 250 (in the experiments, $T^{P o l}$ has been set to 1 ). In order to make the indicators for the effectiveness of the policy comparable, we have to adjust the length of the simulations accordingly such that the total simulation time is $T^{P o l}+500$ months. The business cycle volatility and the average growth rate are then computed for the last 500 months.

We estimate the impact of $T^{P o l}$ on the business cycle volatility and the average growth 
rate with the following GAM:

$$
g=g_{0}+t e\left(\mu, T^{P o l}\right) .
$$

In Figure 20 we depict predictions for the business cycle volatility (left panels) and the average growth rate (right panels) for the three stabilization policies. One can see that especially the average growth rate varies substantially conditioned on different start states where apparently for start states that are lagged by 100 months the growth rate reaches a maximum. Nevertheless, the qualitative results regarding the effects of the three policies stay intact for both, the effect on the business cycle volatility and the average growth rate. This suggests that the start state at which the policy is applied for the first time does not change the qualitative findings of our policy experiments. The policy results are then not only robust against the parametrization but also against the selection of initial start states from possible candidates generated by the pre-simulation.

\section{Discussion and Conclusion}

In this paper we have analyzed three distinctive fiscal policies, each of them aiming at a stabilization of the economy during downturns. The first stabilization policy has been a demand-oriented policy that provides consumption subsidies to households. The two other policies have been supply-oriented policies that provide subsidies to firms in order to encourage them to carry out investments in physical capital. The supply-oriented policies differ from each other in their technological alignment; while the one policy grants subsidies for any investment regardless its technological focus, the payout of subsidies is limited for the other policy to those investments that flow in the best practice technology. The choice of these policies has been motivated by real world examples of stabilization policies contained in economic stimulus packages enacted by the U.S. government during the economic crisis starting in 2008 .

The goal of the policy analysis has been to addressed the following research questions: Are the three policies actually able to stabilize the economy? Do the policies have long-term effects on the economic growth? And if so, do the long-term implications differ between the policies? While the first research question addresses the effectiveness of the policies with respect to their primary goal, the other questions address possible long-term effects that are not the direct purpose of the policies.

We have run extensive simulations of a closed agent-based macro model from which we have obtained robust results. In particular, we have found that all three policies have similar effects on the business cycle volatility. They substantially reduce short-term fluctuations where a higher reduction of the volatility can be achieved by increasing the policy intensity. As a result, there are only little differences between the policies regarding their original aim. Regarding possible growth effects, however, we have obtained a more ambiguous picture. The technology subsidizing policy has a strong growth-enhancing effect that is increasing in the policy intensity. The consumption subsidizing policy leads only to a slight improvement of the average growth rate, where the effect of this policy becomes also stronger with an increasing intensity of the policy. In contrast, the investment subsidizing policy leads to a reduction of economic growth that is not monotonic in the policy intensity; for this policy we could identify a critical policy intensity at which the policy has its greatest negative impact on the average growth rate. Altogether, these observations lead to a striking conclusion: even if the policies are almost equally effective in smoothing the business cycle, they differ substantially regarding their implications for long-term growth.

What are the implications for the economic literature? The question whether stabilization policies have effects on long-term growth has especially been addressed by the endogenous growth literature with inconclusive results. Many studies have concluded possible effects by analyzing the effect of short-term fluctuations on long-term growth without explicitly considering stabilization policies in their analysis. Others have incorporated a (fiscal) stabilization policy, but focused on the automatic stabilizers income tax and unemployment payments without paying attention to a more elaborate design of discretionary stabilization policies. The endogenous growth literature has stressed the importance of structural factors of the models under consideration for the long-term effects of stabilization polices. Struc- 
tural factors can thereby be the assumption regarding the mechanism generating endogenous growth (Schumpeterian models versus learning-by-doing hypothesis) or the source of shocks driving the short-term volatility (monetary versus real shocks). Our analysis suggests that besides those structural aspects also the concrete design of the policy plays an important role for long-term effects of stabilization policies. In that sense, maybe the wrong question has been posed in the literature. Given our findings, the question should not be whether stabilization policies foster or reduce long-term growth, the question should be which stabilization policies foster and which reduce long-term growth.

The results obtained from our policy analysis have also strong implications for policymakers. In general, policymakers can choose from a wide variety of different discretionary policy measures to alleviate an economic downturn. Our policy experiments suggest that different policy opportunities may have different consequences for the economic development in the medium and long run, even if they can equally stabilize the economy in the short run. For our policy examples, we have shown that a policy supporting the speed of technological change seems to be the best choice as it leads to sustainable long-term growth and at the same time to stable prices. The only negative aspect of this policy is its long-term impact on the market concentration. Unlike for the technology policy, we have found more serious conflicts of goals for consumption subsidizing and untargeted investment subsidizing policies. The most striking one can be found for the case of investment subsidization; if the government grants subsidies for any investment without technological targeting, then the short-term stabilization leads to a reduction of long-term growth. For consumption subsidizing policies, one can find a serious conflict especially between short-term stability and the goal of price stability. In that sense, the policy measures contained in the U.S. stimulus package of 2009 with their technology-oriented targeting could be considered as a more appropriate choice for a farsighted stabilization policy. Such a policy would have potential to bring the U.S. economy not only back on its pre-crisis output level but also at a higher long-term growth path. Nevertheless, policymakers should be aware of the fact that any stabilization policy comes at a price. It is then the job of policymakers to carefully assess possible long-terms effects of their candidate policies and to rate which of the possible negative consequences have higher or lower priorities.

\section{A Model setup and Parameter Setting}

Table 1 shows the benchmark parametrization used for the simulations throughout the paper. Table 2 shows the set up of the model with respect to the number of agents used in the simulations. Note that for consumption goods firms Table 2 shows the initial number of firms as the actual number of firms varies over time due to endogenous firm exit and random firm entry. Additionally to the number of agents, the table reports the general skill distribution of households and the general skill specific speeds of the adjustment of specific skills.

\section{B Statistical Analysis with Generalized Additive Mod- els}

We have made an extensive use of Generalized Additive Models with penalized splines to evaluate the policy experiments statistically. There are basically three applications of GAMs in the paper:

1. In the policy experiments we consider a variation of the policy intensity parameter $\mu$ within a range between 0 and a maximum $\mu_{\max }$. The case $\mu=0$ is thereby the case where no policy is applied. In order to show how a variation of this policy parameter changes the behavior of the model, we have run simulations of the model in which we stepwise increased parameter $\mu$. For each value of $\mu$, we have run 12 batch runs and determined the business cycle volatility and the average growth rate for each of the runs. As a result, we have obtained pairs of observations for business cycle volatility and growth from each run, to which we can assign a specific value of $\mu$. In order to 


\begin{tabular}{lll}
\hline Symbol & Name & Value \\
\hline \hline tax & Income tax rate & 0.025 \\
$\kappa$ & Consumption adjustment & 0.001 \\
$\delta$ & Capital depreciation rate & 0.01 \\
$\chi^{S}$ & Service level expected demand & 0.7 \\
$\gamma^{C}$ & Intensity of consumer choice & 12.0 \\
$\rho$ & Discount rate & 0.02 \\
$\Delta q^{i n v}$ & Technological progress & 0.05 \\
$T^{E x}$ & Maximum deferral period & 24 \\
$\sigma^{V}$ & Demand volatility & 0.1 \\
$T^{L T}$ & Investment planning horizon & 60 \\
$\sigma_{D}^{2}$ & Expected variance & 0.1 \\
$T^{L o a n}$ & Debt repayment period & 18 \\
$\omega$ & Debt rescaling factor & 0.50 \\
$r^{c}$ & ECB base rate & 0.03 \\
$m r^{c}$ & ECB rate markdown deposit rate & 0.1 \\
$d^{f}$ & Dividend payout ratio & 0.70 \\
$\bar{d}$ & Threshold full dividends (firms) & 0.5 \\
$\alpha^{b}$ & Basel capital requirement & 10.0 \\
$\beta^{b}$ & Min. cash reserve ratio & 0.10 \\
$h^{F B}$ & Firm birth hazard rate & 0.01 \\
$s^{F}$ & Initial equity for start ups & 4.0 \\
$\varphi$ & Wage update & 0.01 \\
$\psi$ & Wage reservation update & 0.01 \\
$\varrho^{u p}$ & Upper bound firing & 0.1 \\
$\gamma^{\text {gen }}$ & Logit parameter general skills & 0.5 \\
$u$ & Unemployment benefit pct & 0.55 \\
\hline
\end{tabular}

Table 1: Parametrization of the model.

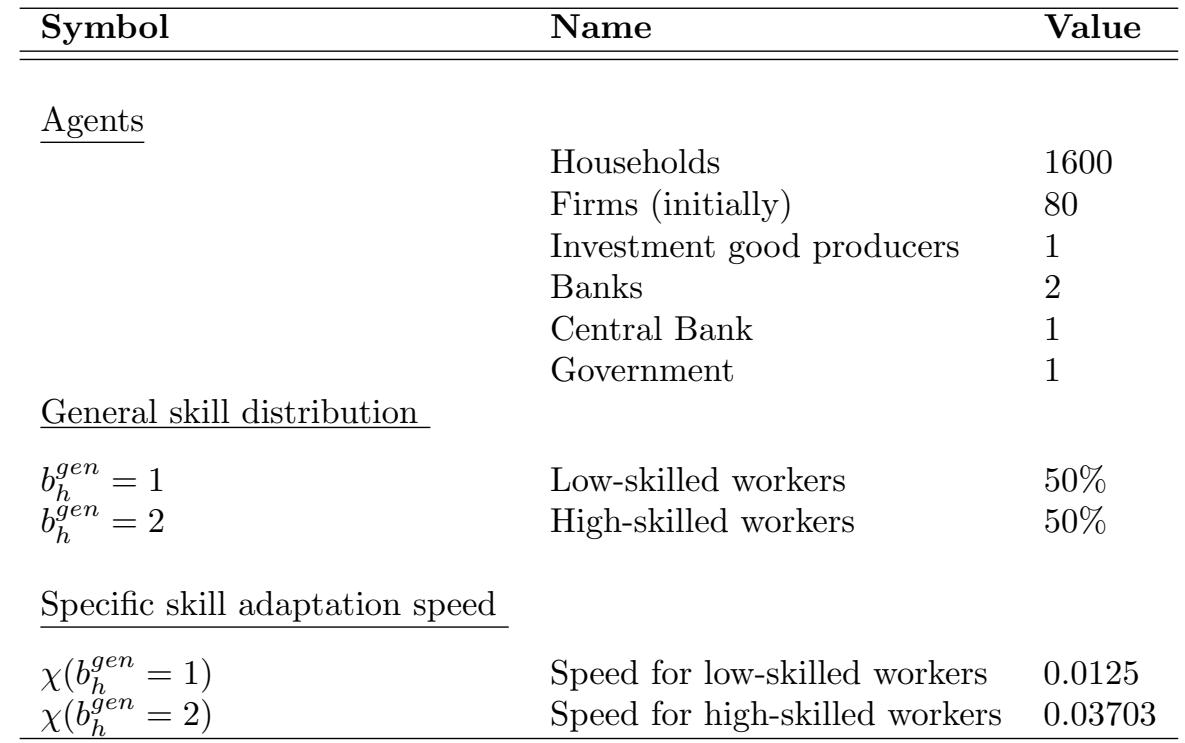

Table 2: Set-up of the model.

measure the effect of $\mu$ on the two indicator variables, we have estimated a GAM that is described by

$$
g=g_{0}+s(\mu)
$$

In this expression, $g$ is the response variable (business cycle volatility or growth rate) that is assumed to be distributed following some exponential family distribution, the policy intensity $\mu$ is the covariate of the statistical model and $g_{0}$ is a parametric 


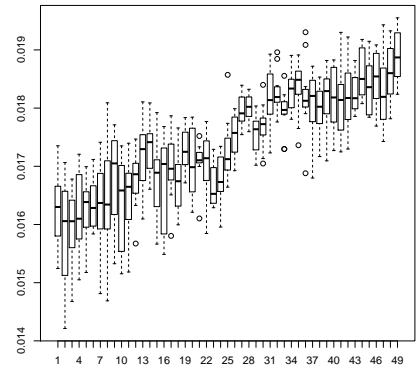

(a)

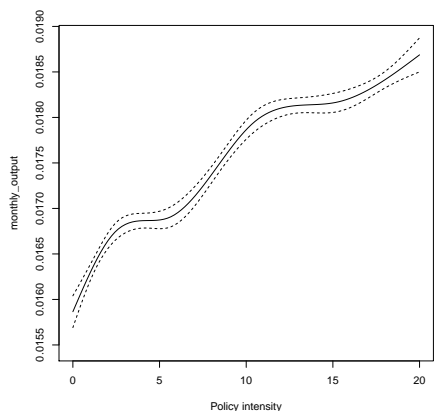

(b)

Figure 21: Left: Box plots for the average growth rates based on simulations for different values of $\mu$. Right: Estimated GAM of the same data.

intercept. The term $s(\mu)$ is an unknown smooth function that depends on covariate $\mu$. Figure 21 illustrates how the single observations for the growth rate under the technology policy are translated into predictions of the GAM.

2. For some variables such as aggregate output, it is of particular interest how the policy effect evolves over time. Therefore, one has to study the effect of $\mu$ on the evolution of time series data. In order to estimate the effect of a variation of $\mu$ statistically, we have set up a statistical model in which the policy effect is statistically co-explained by a second covariate, namely time $t$; to account for both explanatory variables, we have specified a GAM, in which the smooth term jointly depends on $t$ (in quarters) and $\mu$. Technically speaking, since isotropic smooth terms of the sort of $s(t, \mu)$ are only good choices when covariates are on the same scale, which is not the case for $\mu$ and $t$, we opt for tensor product smooth terms to explain the joint effect of policy intensity and time (see Wood, 2006). The GAM is then described by

$$
g=g_{0}+t e(t, \mu)
$$

In Section 4.3, we illustrate the evolution of policy effects with means of heat maps in which the color code indicates the strength of the policy effect estimated from the Spline model with time (at $\mathrm{x}$ axis) and the intensity parameter $\mu$ (at $\mathrm{y}$ axis) as predictor variables. The strength of the effect is thereby determined relative to to baseline scenario without policy. In particular, it is determined either by

$$
g^{e f f}=\frac{g_{0}+t e(t, \mu)}{g_{0}+t e(t, \mu=0)}
$$

or by

$$
g^{e f f}=t e(t, \mu)-t e(t, \mu=0),
$$

depending on whether aggregates (e.g. total output) or rates (e.g. growth rates) are considered.

3. GAMs have also been used for the robustness checks of the policy results as described in Section 4.4 .

The GAMs have been estimated with the statistic software R using the function gam() from the mgcv package (e.g., Wood, 2011).

\section{References}

Aghion, P., G.-M. Angeletos, A. Banerjee, and K. Manova (2005): "Volatility and growth: Credit constraints and productivity-enhancing investment," Tech. rep., National Bureau of Economic Research. 
Aghion, P. and G. Saint-Paul (1998): "Virtues of bad times interaction between productivity growth and economic fluctuations," Macroeconomic Dynamics, 2, 322-344.

Allen, T. And C. Carrol (2001): "Individual Learning about Consumption," Macroeconomic Dynamics, 5, 255-271.

Arifovic, J., J. Bullard, And O. Kostyshyna (2013): "Social learning and monetary policy rules*," The Economic Journal, 123, 38-76.

Ashraf, Q., B. Gershman, And P. Howitt (2011): "Banks, Market Organization, and Macroeconomic Performance: An Agent-Based Computational Analysis," NBER working paper 17102 .

(2012): "How Inflation Affects Macroeconomic Performance: An Agent-Based Computational Investigation," NBER working paper 18225.

Bahk, B.-H. AND M. GorT (1993): "Decomposing Learning by Doing in New Plants," Journal of Political Economy, 101, 561-583.

BAXter, M. AND R. G. King (1999): "Measuring business cycles: approximate band-pass filters for economic time series," Review of economics and statistics, 81, 575-593.

Benaroch, M. and R. J. Kauffman (1999): "A Case for Using Real Option Pricing Analysis to Evaluate Information Technology Project Investments," Information Systems Research, 10, 70-86.

Bils, M. and Y. Chang (2000): "Understanding How Price Responds to Costs and Production," Carnegie-Rochester Conference Series on Public Policy, 52, 33-77.

Blackburn, K. (1999): "Can Stabilisation Policy Reduce Long-run Growth?" The Economic Journal, 109, 67-77.

Blackburn, K. And A. Pelloni (2004): "On the relationship between growth and volatility," Economics Letters, 83, 123-127.

$262-282$.

(2005): "Growth, cycles, and stabilization policy," Oxford Economic Papers, 57,

Blanchard, O. (2008): "The State of Macro," NBER Working Paper 14259.

Blanchard, O., G. Dellariccia, and P. Mauro (2010): "Rethinking macroeconomic policy," Journal of Money, Credit and Banking, 42, 199-215.

Blanchard, O., P. Diamond, R. E. Hall, and J. Yellen (1989): "The Beveridge Curve," Brookings Papers on Economic Activity, 1989, 1-76.

Blanchard, O. AND J. Simon (2001): "The long and large decline in US output volatility," Brookings papers on economic activity, 2001, 135-174.

Broda, C. and J. Parker (2012): "The economic stimulus payments of 2008 and the aggregate demand for consumption," Mimeo, Northwestern University.

Caballero, R. J. and M. L. Hammour (1994): "The Cleansing Effect of Recessions," The American Economic Review, 84, 1350-1368.

Carroll, C. and L. Summers (1991): "Consumption Growth Parallels Income Growth: Some New Evidence," in National Saving and Economic Performance, ed. by B. Bernheim and J. Shoven, Chicago: University of Chicago Press, 305-348.

Comin, D. (2009): "On the integration of growth and business cycles," Empirica, 36, 165176 .

Dawid, H., S. Gemkow, P. Harting, and M. Neugart (2012a): "Labor market integration policies and the convergence of regions: the role of skills and technology diffusion," Journal of Evolutionary Economics, 22, 543-562. 
Dawid, H., S. Gemkow, P. Harting, S. van der Hoog, and M. Neugart (2012b): "The Eurace@Unibi Model: An Agent-Based Macroeconomic Model for Economic Policy Design," Report, Bielefeld University.

Dawid, H. And P. Harting (2012): "Capturing Firm Behavior in Agent-Based Models of Industry Evolution and Macroeconomic Dynamics," in Evolution, Organization and Economic Behavior, ed. by G. Bünsdorf, Edward-Elgar.

Dawid, H., P. Harting, And M. Neugart (2014): "Economic convergence: policy implications from a heterogeneous agent model," Journal of Economic Dynamics and Control, $44,54-80$.

Dawid, H. And M. Neugart (2011): "Agent-based Models for Economic Policy Design," $37,44-50$.

Deaton, A. (1991): "Saving and Liquidity Constraints," Econometrica, 59, 1221-1248.

Delli Gatti, D., M. Gallegati, B. Greenwald, A. Russo, and J. Stiglitz (2010): "The financial accelerator in an evolving credit network," Journal of Economic Dynamics and Control, 34, 1627-1650.

Doms, M. And T. Dunne (1998): "Capital adjustment patterns in manufacturing plants," Review of economic dynamics, 1, 409-429.

Dosi, G., G. Fagiolo, M. Napoletano, and A. Roventini (2013): "income distribution, credit and fiscal policies in an agent-based Keynesian model," Journal of Economic Dynamics and Control, 37, 1598-1625.

Dosi, G., G. Fagiolo, And A. Roventini (2006): "An evolutionary model of endogeneous business cycles," Computational Economics, 27, 3-34.

(2010): "Schumpeter meeting Keynes: A policy-friendly model of endogenous growth and business cycles," Journal of Economic Dynamics and Control, 34, 1748-1767.

Eichenbaum, M. (1997): "Some thoughts on practical stabilization policy," The American Economic Review, 236-239.

Fagiolo, G., A. Moneta, And P. Windrum (2007): "Empirical Validation of AgentBased Models: Alternatives and Prospects," Journal of Artificial Societies and Social Simulation, 10 .

Gaggl, P. And S. Steindl (2008): "On Business Cycle Models and their Extensions to Endogenous Growth Theory," Available at SSRN 1317491.

Gintis, H. (2007): "The Dynamics of General Equilibrium," Economic Journal, 117, 12801309.

Greenwood, J., Z. Hercowitz, and P. Krusell (1997): "Long-Run Implications of Investment-Specific Technological Change," American Economic Review, 87, 342-362.

Harting, P. (2014): "Policy design in the Presence of Technological Change - An Agentbased Approach," Dissertation, Bielefeld University.

Hodrick, R. J. And E. C. Prescott (1997): "Postwar US business cycles: an empirical investigation," Journal of Money, Credit, and Banking, 29, 1-16.

LeBaron, B. And L. Tesfatsion (2008): "Modeling macroeconomies as open-ended systems of interacting agents," American Economic Review: Papers and Proceedings, 98, $246-250$.

Lucas, R. E. And T. J. SARgent (1979): "After Keynesian Macroeconomics," in Rational expectations and econometric practice, ed. by R. Lucas and T. Sargent, University of Minnesota Press. 
Malhotra, N. (1984): "The Use of Linear Logit Models in Marketing Research," Journal of Marketing research, 11, 20-31.

Martin, P. And C. A. Rogers (1997): "Stabilization policy, learning-by-doing, and economic growth," Oxford Economic Papers, 49, 152-166.

(2000): "Long-term growth and short-term economic instability," European Economic Review, 44, 359-381.

Nelson, C. R. And C. I. Plosser (1982): "Trends and random walks in macroeconmic time series: some evidence and implications," Journal of monetary economics, 10, 139162.

OECD (2010a): "Fiscal policy," in OECD Factbook: 2010 Environmental and Social Statistics, ed. by OECD Publishing, http://dx.doi.org/10.1787/factbook-2010-106-en.

(2010b): "Gross Domestic Product," in OECD Factbook: 2010 Environmental and Social Statistics, ed. by OECD Publishing, http://dx.doi.org/10.1787/factbook-2010-97en.

Priesmeier, C. AND N. Stähler (2011): "Long dark shadows or innovative spirits? The effects of (smoothing) business cycles on economic growth: A survey of the literature," Journal of Economic Surveys, 25, 898-912.

Raberto, M., A. Telgio, and S. Cincotti (2012): "Debt, deleveraging and business cycles: an agent-based perspective," Economics, The Open-Access, Open-Assessment EJournal, 6.

Riccetti, L., A. Russo, And M. Gallegati (2013): "Leveraged network-based financial accelerator," Journal of Economic Dynamics and Control, 37, 1626-1640.

Saint-Paul, G. (1997): "Business cycles and long-run growth," Oxford Review of Economic Policy, 13, 145-153.

Silver, E., D. Pyke, AND R. Peterson (1998): Inventory Management and Production Planing and Scheduling, John Wiley \& Sons.

Sorensen, P. And H. Whitta-Jacobsen (2005): Introducing Advanced Macroeconomics: Growth $\&$ Business Cycles, Mc Graw Hil, Maidenhead, UK.

Stadler, G. W. (1990): "Business cycle models with endogenous technology," The American Economic Review, 80, 763-778.

Stock, J. And M. WATson (1999): "Business cycles fluctuations and U.S. macroeconomic time series," in Handbook of Macroeconomics, Vol. 1, ed. by J. Taylor and M. Woodford, Amsterdam: Elsevier, 3-64.

Stock, J. H. And M. W. Watson (2003): "Has the business cycle changed and why?" in NBER Macroeconomics Annual 2002, Volume 17, MIT Press, 159-230.

Summers, P. M. (2005): "What caused the Great Moderation? Some cross-country evidence," Economic Review-Federal Reserve Bank of Kansas City, 90, 6-32.

Wolf, S., S. Fürst, A. Mandel, W. Lass, D. Lincke, F. Pablo-Martí, and C. JAEger (2013): "A multi-agent model of several economic regions," Environmental Modelling \& Software, 44, 25-43.

Wood, S. N. (2006): Generalized Additive Models - An Introduction with $R$, Chapman \& Hall/CRC: Boca raton, FL.

(2011): "Fast stable restricted maximum likelihood and marginal likelihood estimation of semiparametric generalized linear models," Journal of the Royal Statistical Society: Series B (Statistical Methodology), 73, 3-36.

Woodford, M. (2009): "Convergence in macroeconomics: elements of the new synthesis," American Economic Journal: Macroeconomics, 1, 267-279. 